\title{
Experimental analysis of the effects of liquid phase surface tension on the hydrodynamics and mass transfer in a square bubble column
}

\author{
Sanaa Kouzbour ${ }^{1,2}$, Bouchaib Gourich ${ }^{1}$, Youssef Stiriba ${ }^{3}$, Christophe Vial $^{2}$, Fabrice Gros ${ }^{2}$, \\ Rahmat Soutudeh-Gharebagh ${ }^{4}$
}

${ }^{1}$ Laboratory of Process and Environmental Engineering, Higher School of Technology Casablanca, Hassan II University, Route del Jadida, km 7 - BP 8012 Oasis, Casablanca, Morocco.

${ }^{2}$ Université Clermont Auvergne, CNRS, SIGMA Clermont, Institut Pascal, F-63000 Clermont-Ferrand, France

${ }^{3}$ ETSEQ, Departement d'Enginyeria Mecanica, Universitat Rovira i Virgili, Av. Paisos Catalans 26, 43007, Tarragona, Spain

${ }^{4}$ Multiphase Systems Research Lab, School of Chemical Engineering, University of Tehran, P.O. Box 11155/4563, Tehran, Iran

Corresponding author: gourichb@gmail.com

\begin{abstract}
The effects of liquid surface tension were investigated on gas-liquid interfaces in bubbly flows through the analysis of hydrodynamic and mass transfer features. Tap water and aqueous solutions with two types of surfactant (cationic and anionic) are used as aqueous liquid phases. In fact, these surfactants are organic collectors consisting of an amine and ester. The influences of surfactant concentration and superficial gas velocity on the volumetric mass transfer coefficient and the gas hold-up were highlighted. The experimental findings revealed that although the two surfactants tested generated a decrease in surface tension, their effects on gas hold-up and flow regimes are very different. First, it was observed that the gas hold-up in amine aqueous solutions was very close to that in tap water, but it increased once the superficial gas velocity was above $7 \mathrm{~cm} \cdot \mathrm{s}^{-1}$. Conversely, the presence of ester decreased the overall gas holdup since bubble net coalescence was enhanced, and the heterogeneous flow regime prevailed above $2.9 \mathrm{~cm} . \mathrm{s}^{-1}$. Thus, the homogeneous regime prevailed with superficial gas velocity less than $4.4 \mathrm{~cm} . \mathrm{s}^{-1}$ for tap water and amine aqueous solution, which corresponds to the transition point. Experimental findings exhibited also that the power spectral density of pressure fluctuations is a convenient tool to identify the prevailing flow regimes even in surfactant
\end{abstract}


aqueous solutions. Besides that, both organic surfactants strongly reduced the volumetric mass transfer coefficient in comparison to tap water, mainly by inducing an additional resistance to gas-liquid mass transfer through interfacial adsorption for the cationic amine, but by promoting bubble coalescence for the anionic ester aqueous solution.

Keywords: Bubble column; Gas-liquid interfaces; Surface tension; Gas hold-up; Flow regime transition; Mass transfer. 


\section{Introduction}

Gas-liquid and gas-liquid-solid contactors constitute a vital component for many industrial processes. Bubble columns are one of the most widely used multiphase reactors, that are found in many industries such as chemical, biochemical, biotechnology, environmental separation, and wastewater treatment industries [1,2]. In fact, the extensive use of bubble columns is attributed to the advantages they offer, which are mainly good mixing, a better mass and heat transfer rates with low energy intake [3,4]. Meanwhile, optimization and design of bubble columns involve a thorough comprehension of the different flow regimes, as the hydrodynamic characteristics of these regimes are often quite distinct [5]. Essentially, two flow regimes are observed: the homogeneous bubbly flow, and the heterogeneous or churn-turbulent flow regimes. The former is associated with low superficial gas velocities and characterized by a uniform bubble size distribution. The latter is commonly observed at relatively high superficial gas velocities and marked by a wide variety of bubble sizes as a consequence of high coalescence and breakage phenomena.

The knowledge of the hydrodynamic parameters is crucial since it affects the mass and heat transfer phenomena as well as the mixing time in the reactor, which then leads to the reaction rate determination. However, the gas hold-up, which is a key hydrodynamic parameter, is strongly influenced by the geometrical parameters of the column (which usually cover the column diameter $\mathrm{d}_{\mathrm{C}}$ and the ratio between the liquid free level $\mathrm{H}_{0}$ and $\mathrm{d}_{\mathrm{C}}$ ), sparger design, and the physico-chemical properties of gas and liquid phases. Among the liquid properties, surface tension and viscosity were the focus of several investigations [4,6-9]. Since modifying the surface tension through surfactants is of prime importance in most industrial applications, researchers used a variety of organic (alcohols such as ethanol) and inorganic surfactants (electrolytes like $\mathrm{NaCl}, \mathrm{CaCl}_{2}, \mathrm{Na}_{2} \mathrm{SO}_{4}$ ) to provide insight into the effect of surface tension changing on gas hold-up as well as flow regimes. In addition, in the literature, there is an agreement that diminishing the surface tension has been associated with a decrease in bubble coalescence frequency, and then bubbles became smaller, which subsequently leads to an increase in gas hold-up compared to that of the water-air system [10,11]. Bearing in mind that Lu et al. [9] reported that surfactants delay coalescence by slowing the drainage of the liquid film separating the approaching bubbles before they make contact. Furthermore, a large number of correlations have been proposed to properly predict the gas hold-up in two-phase bubble columns, taking into account the type of liquid phase and other parameters (Table 1). 
The flow regime in the bubble column is a multifaceted function of fluid properties, column diameter, gas spargers design, and the operating conditions. Thus, several experimental techniques have been developed and used for this end, including particle image velocimetry [12], electrical resistance tomography [13], laser Doppler anemometry [14], bed vibration signature [15], optical fiber signals [16] and pressure fluctuations [17]. Particularly, the measurement of pressure fluctuations is experimentally simple and inexpensive. It can be used on a laboratory and industrial-scale without altering the flow in the reactor [17]. For this reason, the pressure fluctuations are sampled by a series of pressure transducers located along the column and several approaches, and data analysis techniques are applied to determine the hydrodynamic features and characterize the flow dynamics within the column. Table 2 reports some studies based on pressure fluctuations analysis.

As previously quoted, surfactants play a prominent role in several industrial applications, one illustrative example of which is the flotation process in the mining industry. Indeed, collectors are part of the most important components involved in the flotation process of minerals, such as phosphate, to separate the ore from impurities (e.g. silicates and carbonates in the case of phosphate ore) [18]. The main objective of the collector is to selectively form a hydrophobic layer on a mineral surface in the flotation pulp, and hence ensure the conditions for the attachment of hydrophobic particles to the air bubbles and recovery of these particles in the froth [19]. Basically, a flotation collector is composed of polar and non-polar groups. The nonpolar part, as a linear, branched, or cyclic hydrocarbon group is referred to a hydrophobic group. The polar part, which has a high affinity for mineral surfaces, is known as the minerophilic group [20]. Depending on the tendency of collectors to dissociate in water, they can be divided into three separate groups: cationic, anionic, and non-ionic surfactants [21,22]. Moreover, the surface-active character is imparted by the affinity of the hydrocarbon chain to the gaseous phase, and by that of the polar head to the liquid phase. The surfactant molecule is therefore oriented at the air-water interface [18]. However, as surface-active agents, these collectors significantly affect gas-liquid interfaces. The aim of this study is, therefore, to investigate these specific effects.

Another determining factor in the performance of multiphase contactors is the gas-liquid mass transfer, which is characterized by the volumetric mass transfer coefficient $\mathrm{k}_{\mathrm{L}} \mathrm{a}_{\mathrm{L}}$. In the mineral processing of phosphate ore, a large amount of freshwater (around $500 \mathrm{~m}^{3} \cdot \mathrm{h}^{-1}$ ) is consumed and subsequently about $10,000 \mathrm{~m}^{3}$ of wastewater effluents are generated (case of a Jordanian phosphate industry) [23]. However, flotation wastewaters which contain excess and unreacted 
concentrations of organic surfactants, lead to a serious environmental pollution by degrading water quality and aquatic life [24,25]. Hence, chemical treatments such aeration, oxygenation, ozonation and peroxide or permanganate treatment have been carried out to remove these organic chemicals, though these methods are costly and can bring about a secondary pollution $[25,26]$. Furthermore, biodegradation techniques have attracted interest as a versatile, low-cost, stable and environmentally friendly technique for flotation wastewater treatment [26,27]. On the one hand, in such treatments, mass transfer is a major limiting factor as the oxygen transfer process requires a large amount of energy and of course a high investment cost [28]. On the other hand, the presence of surfactant in wastewater has a very pronounced effect on gas-liquid mass transfer through a modification of the solubility, mobility and specifically the surface tension of the fluids [28].

However, the mass transfer rate strongly relies on the hydrodynamic conditions in bubble columns; and so many parameters affect $\mathrm{k}_{\mathrm{L}} \mathrm{a}_{\mathrm{L}}$, such as design parameters (column geometry and gas distributor design, etc.) and liquid properties (viscosity, presence of ions inhibiting coalescence, or surfactants adsorption, etc.) [29,30]. Regarding the specific effect of surfactants, it is reflected in the increase in the bubble drag force coefficient and the decrease in the bubble rise velocity since these substances tend to accumulate at the bubble gas-liquid interfaces [31]. Bubbles generated in the presence of surfactants have a tendency to be smaller and slower due to the decline in the coalescence phenomenon [32]. This could have a positive impact on the interfacial area, unlike the liquid side mass transfer coefficients $\left(\mathrm{k}_{\mathrm{L}}\right)$ which considerably decreases [29]. A study was accomplished by Sardeing et al. [33] on the impact of non-ionic, anionic, and cationic surfactants on the liquid-side mass transfer coefficient in gas-liquid systems. They reported that regardless of the liquid phase, three zones could be distinguished with respect to the liquid-side mass transfer coefficient variation with the bubble diameter. For mean bubble diameters less than $1.5 \mathrm{~mm}, \mathrm{k}_{\mathrm{L}}$ values were approximately constant about $10^{-4} \mathrm{~m} . \mathrm{s}^{-1}$ and no effect of the surfactants was observed. For mean bubble diameters higher than $3.5 \mathrm{~mm}, \mathrm{k}_{\mathrm{L}}$ values were almost constant with the diameter, but depended on surfactant concentration. For bubbles with diameters varying from 1.5 to $3.5 \mathrm{~mm}, \mathrm{k}_{\mathrm{L}}$ increased from $10^{-4} \mathrm{~m} . \mathrm{s}^{-1}$ to reach between 1 and $3 \cdot 10^{-4} \mathrm{~m} \cdot \mathrm{s}^{-1}$ at $3.5 \mathrm{~mm}$ diameter based on the charge and the concentration of surfactant. Besides, Jamnongwong et al. [34] concluded that the hydrodynamic characteristics were almost constant for each surfactant concentration examined; hence, only a change in oxygen diffusion coefficient could be responsible for the $\mathrm{k}_{\mathrm{L}}$ decline. 
It can be said that no investigations on the effect of collectors as surface-active agents in a twophase bubble column reactor are reported in the literature. Therefore, this work is aimed at studying the gas hold-up and gas-liquid mass transfer rate in a square bubble column reactor with tap water and aqueous solution of cationic and anionic collectors (an amine and an ester, respectively) which are widely used in phosphate flotation. The influences of the collector concentration and superficial gas velocity $\left(\mathrm{U}_{\mathrm{g}}\right)$ on the overall gas hold-up, the flow regime, and the volumetric mass transfer coefficient $\mathrm{k}_{\mathrm{L}} \mathrm{a}_{\mathrm{L}}$ are examined.

\section{Materials and methods}

\subsection{Experimental setup}

The experimental set-up consists of a square bubble column made of Plexiglas with dimensions $0.2 \mathrm{~m} \times 0.2 \mathrm{~m} \times 3 \mathrm{~m}(\mathrm{~L} \times \mathrm{W} \times \mathrm{H})$. Gas sparging is performed through a perforated plate with 246 holes of $0.9 \mathrm{~mm}$ in diameter at the bottom of the column providing uniform aeration. The gas phase consists of compressed air. The air flow rate is controlled using a calibrated rotameter (Brooks Instrument $^{\circledR}$, GT1000, with a precision of $2 \%$ ), and the superficial gas velocity under atmospheric pressure ranges from 0.75 to $9.44 \mathrm{~cm} . \mathrm{s}^{-1}$. The liquid phase is fed into the column through a valve placed at the bottom of the column. The liquid phase is operated in a batch mode and the clear liquid height $\mathrm{H}_{0}$ is adjusted to $1.65 \mathrm{~m}$. All experiments are carried out at ambient temperature and atmospheric pressure. Fig. 1 displays a schematic drawing of the experimental setup.

\subsection{Surfactants preparation and characterization}

The experiments are conducted by using various liquid phases, which are tap water and surfactants aqueous solution. It is worth noting that surfactants have been carefully selected according to their nature and applications. Thus, two types of commercial collectors are tested, namely, an amine and an ester, which are cationic and anionic surfactants, respectively, supplied by OCP Group ${ }^{1}$. These collectors were chosen mainly because of their wide use for the flotation of oxidized ores, such as phosphate and industrial minerals. The concentrations studied vary between 5 and $50 \mathrm{ppm}$. All solutions were prepared by adding each of the two collectors to tap water while stirring for 10 to 15 minutes at a temperature of $25^{\circ} \mathrm{C}$. Experiments are also repeated with tap water as the reference fluid. The surface tension of each solution is measured using a Krüss tensiometer (K12-Krüss@ $@$, Germany) and the Wilhelmy plate method

\footnotetext{
${ }^{1}$ Office Chérifien des Phosphates, Morocco, https://www.ocpgroup.ma/
} 
with an accuracy of $\pm 1 \mathrm{mN} \cdot \mathrm{m}^{-1}$. Surface tension always reached immediately the equilibrium value, so that only the static surface tension value was retained. The surface tension of tap water and aqueous solutions in different concentrations are summarized in Table 3. From this table, it can be deduced that the Critical Micellar Concentration, which corresponds to a saturated interface, is achieved when collector content is about 20 ppm and 24 ppm for the amine and the ester, respectively.

The rheological studies of the solutions are accomplished by means of an AR-G2 rheometer (TA Instruments, USA) with a $40 \mathrm{~mm}-2^{\circ}$ steel cone geometry. A simple shear study with a shear rate ranging from 1 to $1000 \mathrm{~s}^{-1}$ is performed to determine the apparent viscosity value at $25^{\circ} \mathrm{C}$. The measured apparent viscosity of the solutions is represented in Table 3 . In the case of tap water, the obtained surface tension and apparent viscosity are in accordance with literature data [34].

\subsection{Measuring methods in bubble column}

\subsubsection{Gas hold-up measurements}

The overall gas hold-up in the column is measured using the manometric method. Omitting the acceleration and wall friction participation in the momentum balance, and also assuming that $\rho_{\mathrm{G}} \ll \rho_{\mathrm{L}}$, the gas hold-up can be deducted by the following expression:

$$
\varepsilon_{\mathrm{g}}=1-\frac{\Delta \mathrm{P}}{\rho_{\mathrm{L}} \times \mathrm{g} \times \Delta \mathrm{H}}
$$

where $\Delta \mathrm{P}$ is the difference of static pressure between two sensors placed at a distance $\Delta \mathrm{H}$. Pressure measurements are performed using four piezo-resistive sensors embedded in the wall (Keller PR-25/8797.1), with respective pressure ranges 0 - 500 mbar (for the two lowest sensors), 0 - 150 mbar (for the two top sensors), with an accuracy of $0.02 \%$ of the full scale. The distance between the pressure sensors is $0.5 \mathrm{~m}$ (from $0.5 \mathrm{~m}$ to $2 \mathrm{~m}$ above the gas sparger). Pressure signals are sampled with a 16-bit acquisition card (Adlink-19001, Adlink Technology Inc., Taiwan) and stored in a PC. The Adlink®Utest software is employed to control data acquisition. Pressure signals are sampled with a frequency of $100 \mathrm{~Hz}$ and a duration of $200 \mathrm{~s}$. Thus, the acquisition length is 20,000 points for each experiment. Three samples for each condition are conducted to diminish statistical error.

\subsubsection{Flow regime}

Spectral analysis of pressure signals based on Fast Fourier transform (FFT), which is in the frequency domain analysis, has been illustrated as a simple and robust tool to determine the hydrodynamic regime in bubble columns when water corresponds to liquid phase [35]. 
However, few studies [7,11,36] have applied this tool for systems that contain water contaminated with surfactants or viscous liquids.

In this work, spectral analysis of pressure fluctuations is applied using the equipment used for gas hold-up measurements. Fourier transform allows transposing pressure signals expressed in the time domain into the frequency domain. This leads to the identification of the main frequencies contained in the initial signal. The Fourier transform is given as:

$$
\mathcal{F}_{x}(f)=\frac{1}{T} \int_{0}^{T} P_{x}(t) e^{-2 \pi i f t} d t
$$

The power spectral density (PSD) expresses the contributions of the elementary sine functions to the whole signal:

$$
P S D=\frac{1}{T} E\left(\mathcal{F}_{x} \cdot \mathcal{F}_{x}^{*}\right)
$$

where $\mathrm{E}$ is the expectation of $\mathcal{F}_{x}(f)$ and $\mathcal{F}_{x}^{*}$ is the complex conjugate of the Fourier transform.

It is worth mentioning that the pressure signal in the bubble column changes depending on different fluctuation sources with specific characteristic frequencies, comprising bubble formation, rise, coalescence and breakage, and liquid level fluctuations. Therefore, the amplitude, dominant frequency, and frequency distribution of a PSD curve can be employed to characterize the properties and behavior of the bubbles and to identify the flow patterns in a bubble column.

\subsubsection{Mass transfer coefficient and bubble size measurements}

The volumetric mass transfer coefficient $\mathrm{k}_{\mathrm{L}} \mathrm{a}_{\mathrm{L}}$ is measured using the dynamic deoxygenation method, which is based on oxygen elimination by bubbling nitrogen followed by reoxygenation using compressed air. In the batch liquid phase, the variation of dissolved oxygen concentration in the batch liquid phase with time is measured using two dissolved oxygen electrodes (WTW Cellox 325) located at $0.11 \mathrm{~m}$ and $1.50 \mathrm{~m}$ above the perforated plate, and horizontally immersed to a depth of $9 \mathrm{~cm}$. These sensors are connected to a DO-meter (WTW OXI 197i) and to a data acquisition system (Adlink-1901) allowing the recording of concentration values. The time constant $\left(\mathrm{k}_{\mathrm{p}}\right)$ of the oxygen sensors is measured by the method described by Vandu and Krishna (2004), which give $\mathrm{k}_{\mathrm{p}}=0.14 \mathrm{~s}^{-1}$. A mass balance on dissolved oxygen (and assuming a perfectly stirred bubble column) gives:

$$
\frac{d C_{t}}{d t}=k_{L} a_{L}\left(C_{s}-C_{t}\right)
$$


where $C_{s}$ is the dissolved oxygen concentration at saturation and $C_{t}$ is the instantaneous dissolved oxygen concentration measured by experiments. The integrated formula of Eq. (4) is as follows:

$$
\ln \frac{\mathrm{C}_{\mathrm{s}}-\mathrm{C}_{0}}{\mathrm{C}_{\mathrm{s}}-\mathrm{C}_{\mathrm{t}}}=\mathrm{k}_{\mathrm{L}} \mathrm{a}_{\mathrm{L}} \mathrm{t}
$$

where $\mathrm{C}_{0}$ is the initial dissolved oxygen concentration. The value of $\mathrm{k}_{\mathrm{L}} \mathrm{a}_{\mathrm{L}}$ is obtained from the slope of the curve of $\ln \frac{C_{s}-C_{0}}{C_{s}-C_{t}}$ versus $t$.

The volumetric oxygen transfer coefficients measured at the temperature $\mathrm{T}\left(\mathrm{k}_{\mathrm{L}} \mathrm{a}_{\mathrm{L}_{\mathrm{T}}}\right)$, are reported at $20^{\circ} \mathrm{C}\left(\mathrm{k}_{\mathrm{L}} \mathrm{a}_{\mathrm{L}_{20}}\right)$ using the following temperature correction:

$$
\mathrm{k}_{\mathrm{L}} \mathrm{a}_{\mathrm{L}_{20}}=\mathrm{k}_{\mathrm{L}} \mathrm{a}_{\mathrm{L}_{\mathrm{T}}} \times \theta^{(20-\mathrm{T})} \text { with } \theta=1.024
$$

Bubble size were measured using image analysis. Pictures of the bubbly flow were taken and analysed using the free ImageJ software package (https://imagej.nih.gov/). However, this technique was limited to low gas hold-up, i.e. to low superficial gas velocity, due to the influence of light obscuration by the bubbles on flow imaging.

\section{Results and discussion}

The following section outlines and discusses the experimental results obtained. A contribution to the assessment of the influence of surfactant addition on the hydrodynamics and oxygen mass transfer of bubble column is provided through the analysis and comparison with the literature of parameters such as gas hold-up, transition velocity, and volumetric mass transfer coefficient.

\subsection{Gas hold-up and flow regime transition}

The overall gas hold-up is one of the foremost hydrodynamic and design parameters of bubble columns. It is also strongly affected by surfactants. Figs. $2 \mathrm{a}$ and $2 \mathrm{~b}$ depict the global gas holdup in tap water and surfactant aqueous solutions as a function of superficial gas velocity. $\varepsilon_{\mathrm{g}}$ augments with the increase in $U_{g}$ for any liquid phase. This can be explained by an increase in the number of bubbles in the liquid phase with superficial gas velocity. Besides, at the same superficial gas velocity, the overall gas hold-up of ester aqueous solutions is smaller than that of tap water and this is due to net bubble coalescence that quickly takes place (Fig. 2b). Conversely, the overall gas hold-up in amine aqueous solutions is almost equal to that in tap water at a relatively low gas flow rate, but this is no longer the case for $U_{g}$ greater than $7.3 \mathrm{~cm} . \mathrm{s}^{-}$ ${ }^{1}$ (Fig. 2a). This increase in $\varepsilon_{\mathrm{g}}$ is due to froth formation with a height approximately of 15 to 18 
$\mathrm{cm}$ at high superficial gas velocities (exceeding $7.3 \mathrm{~cm} \cdot \mathrm{s}^{-1}$ ). As mentioned by Besagni et al. [37], the formation of a thick cap was noticed in the upper part of the column; thus, this cap hinders air disengagement and subsequently causes bubble accumulation and a significant increase in $\varepsilon_{\mathrm{g}}$. Fig. 3a displays the overall gas hold-up differences between the amine and the ester compared to tap water at a concentration of $50 \mathrm{ppm}$. The difference between both surfactants seems to result from their charge at constant $\mathrm{pH}$, as surface tension does not strongly differ (Table 3) and gas-liquid interfaces seem to be saturated by adsorbed species above 10 ppm for both surfactants whatever the superficial gas velocity (Fig. $3 \mathrm{~b}$ and 3c). Similarly, the effect of the axial position in the column does not strongly affect these conclusions (Fig. 4). The obtained findings are in line with those of Koide et al. [38], and Yagi and Yoshida [39] by using surfactants and antifoam agents. Conversely, the majority of studies found that $\varepsilon_{\mathrm{g}}$ improved in the presence of surface-active agents $[8,10,11]$. Hence, it emerges from the literature that the effect of surfactants can be complex and does not always induce an increase in the gas hold-up.

The experimental data were compared to five correlations found in the literature (Table 1) to examine their validity in this case. Fig. 5 depicts the comparison between experimental and predicted $\varepsilon_{\mathrm{g}}$ for tap water and surfactant aqueous solutions. For the case of tap water (Fig. 5a), most correlations were approximately able to predict $\varepsilon_{\mathrm{g}}$ in the homogeneous regime, but then the $\varepsilon_{\mathrm{g}}$ was overpredicted for $\mathrm{U}_{\mathrm{g}}>2 \mathrm{~cm} . \mathrm{s}^{-1}$. Whereas, the correlations by Kumar et al. [40] and Hikita and Kikukawa [41] better predict $\varepsilon_{\mathrm{g}}$, Meanwhile, these correlations overpredict $\varepsilon_{\mathrm{g}}$ for both amine and ester aqueous solutions (50 ppm), which means that it is unable to predict the effect of liquid phase properties on gas hold-up through these correlations (Fig. 5b and 5c). However, for amine aqueous solution $(50 \mathrm{ppm})$ and at all $\mathrm{U}_{\mathrm{g}}$, the correlation suggested by Hughmark [42] better predicts $\varepsilon_{\mathrm{g}}$ than other correlations, while the $\varepsilon_{\mathrm{g}}$ values predicted by the Reilly et al. [43] correlation are very close to the experimental values but at high velocities (Fig. $5 b)$.

Concerning the flow regime, it is clear from Fig. 3a that up to $4.42 \mathrm{~cm} . \mathrm{s}^{-1}$, the relationship between $\varepsilon_{\mathrm{g}}$ and $\mathrm{U}_{\mathrm{g}}$ is linear for air-tap water or air-tap water-amine, which means that amine concentration has no effect on $\varepsilon_{\mathrm{g}}$ in this range of superficial gas velocity. However, the gas hold-up is influenced by the type of gas distributor used which mostly generates gas bubbles with a diameter of around $1 \mathrm{~mm}$. The linearity of the curve thus shows that the homogeneous regime prevails at $U_{g}$ less than $4.4 \mathrm{~cm} . \mathrm{s}^{-1}$. Beyond this critical gas superficial velocity, the gas 
hold-up keeps augmenting, but the slope is gradually reduced. This means that the transitional regime takes place. The slope and shape of the gas hold-up curve for the water-air system are those generally found for a similar type of gas distributor used in this study [10]. During the transition flow regime, clusters of bubbles appear and rise through the column center with lower mean residence time of the gas phase, thing that was also noticed in the literature. As for the air-water-ester system, bubble coalescence occurs even at low superficial gas velocity, leading to the onset of the heterogeneous flow regime from the beginning. Thus, large bubbles appear and rise more rapidly than the smaller ones, which reduces the overall gas hold-up. These findings are in agreement with literature data $[4,10,44]$.

Furthermore, two different methods were utilized by several authors $[4,11]$ to detect the regime transition point: swarm velocity method and the drift flux model. The first one was developed by Zuber and Findlay [45] and based on the swarm velocity:

$$
\mathrm{U}_{\mathrm{swarm}}=\frac{\mathrm{U}_{\mathrm{g}}}{\varepsilon_{\mathrm{g}}}
$$

The swarm velocity $U_{\text {swarm }}$ is plotted against the superficial gas velocity. $U_{\text {swarm }}$ remains constant in the homogeneous regime but starts to augment when the system reaches the heterogeneous regime. Indeed, the sudden increase of the swarm velocity; which is due to the occurrence of the first large bubble; is a sign of the flow regime transition.

The second method to determine the transition velocity was the drift flux model proposed by Wallis [46]. In a bubble column operated in the batch mode for the liquid phase, the drift flux is expressed as:

$$
\mathrm{j}_{\mathrm{gl}}=\mathrm{U}_{\mathrm{g}}\left(1-\varepsilon_{\mathrm{g}} \mathrm{C}_{0}\right)
$$

$\mathrm{C}_{0}$ is the distribution parameter which equals to 1 when the flow is radially uniform. Assuming $\mathrm{C}_{0}=1$ in the homogeneous flow regime, a change in the slope in the $\mathrm{j}_{\mathrm{gl}}=\mathrm{U}_{\mathrm{g}}\left(1-\varepsilon_{\mathrm{g}}\right)$ drift flux versus $\varepsilon_{\mathrm{g}}$ plot can be regarded as a transition point. Figs. $6 \mathrm{a}$ and $6 \mathrm{~b}$ represent the drift flux and the swarm velocity plot for all solutions. According to Fig. 6a, a rapid change in slope was observed in the drift flux curve for the $50 \mathrm{ppm}$ ester aqueous solution which corresponds to a superficial gas velocity of $2.9 \mathrm{~cm} . \mathrm{s}^{-1}$. Similar results have been reported in the literature in the case of viscous liquids, such as glucose, and carboxymethyl cellulose (CMC) aqueous solution [7]. Meanwhile, the drift flux curve of the water-air system shows notable change at a gas holdup of about $18 \%$, which confirms that the transition occurs at a superficial gas velocity of 4.42 
$\mathrm{cm} . \mathrm{s}^{-1}$. Moreover, Fig. $6 \mathrm{~b}$ clearly exhibits the influence of ester addition on the flow regime by advancing the occurrence of large coalesced bubbles (Fig. 7), which leads to a destabilization of the homogeneous flow, and therefore, the transition appears earlier and then, the heterogeneous flow regime is rapidly developed, even at relatively low ester concentration. This finally highlights that despite the adsorption of the ester collector, this does not prevent bubble coalescence.

\subsection{Spectral analysis of the pressure time series}

In this section, the pressure time series recorded by the sensors in position 1 and 3 for tap water and surfactant aqueous solutions and different superficial gas velocities are processed. The PSD of the pressure signal is estimated on time series of 20,000 points, divided into segments of 512 points each, with an overlap of $10 \%$ of this block length, and a Hamming window as the window function. Given that in bubble columns only phenomena with a frequency range between 0 and $20 \mathrm{~Hz}$ happen [47], the PSD curves are, therefore, plotted only in this range. Figs. 8a, 8b and $8 \mathrm{c}$ exhibit the PSD for different operating solutions at three superficial gas velocities: $2.2 \mathrm{~cm} . \mathrm{s}^{-}$ $1,5.4 \mathrm{~cm} . \mathrm{s}^{-1}$, and $9.4 \mathrm{~cm} \cdot \mathrm{s}^{-1}$, respectively. At low superficial gas velocity $\left(\mathrm{U}_{\mathrm{g}}=2.2 \mathrm{~cm} . \mathrm{s}^{-1}\right)$, and for both tap water and amine aqueous solution (50 ppm) (Figs. 8a and 8b), the PSD plots show a peak at $0.1 \mathrm{~Hz}$, which corresponds to the homogeneous regime. Hence, for the tap water-air system, the obtained results are in accordance with Drahoš et al. [47] and Vial et al. [35] who reported that the homogeneous regime was dominated by very low frequencies of the order of $0.1 \mathrm{~Hz}$, corresponding to liquid level oscillations. In contrast, the PSD plot of an ester aqueous solution (Fig. 8c) exhibits a dominant peak at a frequency of about $5.8 \mathrm{~Hz}$, indicating the formation of large bubbles even at low superficial gas velocity, corresponding to frequency of the alternative upward-downward move of the bubble close to the wall. As this could have been noticed early, the addition of ester decreases the liquid turbulence and promotes bubble coalescence.

As illustrated in Figs. 8a-c, the increase in the superficial gas velocity $\left(5.4 \mathrm{~cm} . \mathrm{s}^{-1}\right)$ is accompanied by the appearance of secondary peaks at low frequency, as well as the increase in the amplitudes of the dominant peaks. This is due to the increase in the gas throughputs by augmenting the superficial gas velocity, which leads to an increase in the coalescence rate and, subsequently, of the bubble size. Moreover, for ester aqueous solution, the dominant peak appears this time at lower frequency of about $4.2 \mathrm{~Hz}$ (less than that for lower $\mathrm{U}_{\mathrm{g}}$ ), which confirms that the bubble coalescence becomes dominant, leading to the formation of larger 
bubbles. On the other hand, the transition region is characterized by the presence of two peaks, as seen in the PSD plot of tap water (Fig. $8 \mathrm{a}$ and at $\mathrm{U}_{\mathrm{g}}=5.4 \mathrm{~cm} \cdot \mathrm{s}^{-1}$ ). At high superficial gas velocity such as $9.4 \mathrm{~cm} \cdot \mathrm{s}^{-1}$ (Figs. $8 \mathrm{a}-\mathrm{c}$ ), for both tap water and amine aqueous solution (50 ppm), the PSD plots show a broader peak in the range 2-5 Hz, which corresponds to the heterogeneous regime. In addition, the secondary peaks mentioned above are fully developed in almost all cases, which can be caused by the existence of two different bubble populations at this high superficial gas velocity (due to the phenomena of bubble coalescence and break-up).

The average frequency of the spectrum, $\mathrm{f}_{\mathrm{m}}$, is another valuable parameter that may provide useful information about the phenomena that occur in the bubble column. The average frequency of a spectrum is given as:

$$
f_{m}=\frac{\int\left[P_{x x}(f)\right] f d f}{\int\left[P_{x x}(f)\right] d f}
$$

where $P_{x x}(f)$ is the average power spectral density $\left(\mathrm{Pa}^{2} . s\right)$. The average frequency versus superficial gas velocity for tap water and surfactant aqueous solutions is plotted in Fig. 9. This shows that the average frequency $\mathrm{f}_{\mathrm{m}}$ increases by rising the gas velocity. In fact, the average frequency is close to 0 in the homogeneous regime, whereas it is between 3 and $5 \mathrm{~Hz}$ in the heterogeneous regime.

In conclusion, the findings derived from the power spectral density of the pressure time series are in good agreement with those obtained by other measuring techniques in this study.

\subsection{Gas-liquid mass transfer performance in bubble column}

After identifying the different flow regimes from the evolution of the gas fraction and the analysis of pressure time series, the volumetric mass transfer coefficient has still to be measured, as it both results from bubble size and it assesses the role of surface-active agents at the gas-liquid interface. Fig. 10 represents the temporal variation of dissolved oxygen concentration in tap water and surfactant aqueous solutions at a concentration of $50 \mathrm{ppm}$ and a superficial gas velocity of $2.2 \mathrm{~cm} \cdot \mathrm{s}^{-1}$. From this figure, it can be deduced that the mass transfer rate in tap water was greater than surfactant aqueous solutions, especially at the initial stage. This proves that the liquid phase properties have a significant effect on the gas-liquid mass transfer performance.

As well known, the volumetric mass transfer coefficient is strongly dependent on the superficial gas velocity (Fig. 11). Therefore, for all operating conditions, $\mathrm{k}_{\mathrm{L}} \mathrm{a}_{\mathrm{L}}$ increased with superficial 
gas velocity. In fact, as mentioned by Dong et al. [48], with the increase in $U_{g}$, the number of bubbles in the liquid phase raised and the turbulence induced by the rising bubbles was enhanced, which allowed to drastically increase the gas-liquid contact area and subsequently improve the performance of the gas-liquid mass transfer. This is due to the fact that any surfaceactive agent, as the amine or the ester, reduced surface tension (Table 3). However, adsorbed species are also known to induce an additional interfacial resistance to mass transfer, especially when a saturated interface which creates an additional interfacial resistance to mass transfer; small bubbles behave with rigid interfaces, resulting in a lower mass transfer coefficient. Thus, by reducing the surface tension, adsorbed surfactants influence the gas-liquid interface as well as the gas-liquid mass transfer.

Fig. 11 shows the evolution of volumetric mass transfer coefficient $\mathrm{k}_{\mathrm{L}} \mathrm{a}_{\mathrm{L}}$ depending on the superficial gas velocity for tap water and surfactant aqueous solutions under different concentrations. In these figures, $\mathrm{k}_{\mathrm{L}} \mathrm{a}_{\mathrm{L}}$ in tap water was higher than in amine and ester aqueous solutions, which means that these two surfactants have a large effect on gas-liquid mass transfer. Furthermore, for both types of surface-active agent, the volumetric mass transfer coefficient decreased slightly with increasing surfactant concentration from $5 \mathrm{ppm}$ to $50 \mathrm{ppm}$, except for the case of high superficial gas velocities $\left(\geq 6.02 \mathrm{~cm} \cdot \mathrm{s}^{-1}\right)$ where $\mathrm{k}_{\mathrm{L}} \mathrm{a}_{\mathrm{L}}$ at $50 \mathrm{ppm}$ was distinctly lower from that at $5 \mathrm{ppm}$. This slight effect of surfactant concentration was also shown in the case of gas hold-up (Fig. 3). According to Nock et al. [49], when attaching to a bubble, the surface flow around the bubble redistributes the surfactants to the base of the bubble, producing a surface tension gradient and a Marangoni effect. Indeed, the decrease in the surface tension can reduce the internal circulation within a bubble, which increases the drag force and decreases the rise velocity, and then causes a decrease in $\mathrm{k}_{\mathrm{L}}$. In contrast, as the diameter of the bubble was larger in aqueous ester solutions, the increase in the gas-liquid contact area with the superficial gas velocity was limited. Hence, the reinforcing effect of the increase in the superficial gas velocity on the volumetric mass transfer coefficient of oxygen in surfactant aqueous solutions was attenuated.

Besides the liquid phase properties, other parameters influence the volumetric mass transfer coefficient estimation: namely, the operating conditions, and the geometrical parameters of the bubble column, but also the position of the oxygen sensor. Actually, there are two main cases reported in the literature; the oxygen sensor placed either at $5 \mathrm{~cm}$ to $10 \mathrm{~cm}$ from the gas distributor [50], or far from the gas sparger [48]. Figs. 12a and 12b illustrate the change of volumetric mass transfer coefficient with the variation of oxygen sensor position for tap water 
and the ester aqueous solution. In these figures, the volumetric mass transfer coefficient obtained at $0.11 \mathrm{~m}$ from the gas sparger was lower than those obtained at $1.50 \mathrm{~m}$. This can be explained by the fact that in the area close to the gas distributor $(11 \mathrm{~cm}), \mathrm{k}_{\mathrm{L}} \mathrm{a}_{\mathrm{L}}$ is measured in the region where the primary gas distribution predominates, which can widely differ from the bubble size distribution in the bulk particularly for ester aqueous solution where coalescence occurred easily; this means that the bubble size distribution changed above the first $0.11 \mathrm{~m}$ close to the sparger. However, when the probe is far from the sparger, there may be a time lag between the change in gas composition and the start of the effective measurement at the probe level [51]. For these reasons, Shioya and Dunn [52] suggested that the oxygen sensor should be placed at liquid mid-height in bubble columns.

According to Chisti [53], the volumetric mass transfer coefficient $\left(\mathrm{k}_{\mathrm{L}} \mathrm{a}_{\mathrm{L}}\right)$, the gas hold-up $\left(\varepsilon_{\mathrm{g}}\right)$, the mean bubble diameter $\left(\mathrm{d}_{\mathrm{B}}\right)$ and the mass transfer coefficient $\left(\mathrm{k}_{\mathrm{L}}\right)$ are known to be linked by Eq.(10):

$$
\frac{\mathrm{k}_{\mathrm{L}}}{\mathrm{d}_{\mathrm{B}}}=\mathrm{k}_{\mathrm{L}} \mathrm{a}_{\mathrm{L}} \frac{\left(1-\varepsilon_{\mathrm{g}}\right)}{6 \varepsilon_{\mathrm{g}}}
$$

For the air-water and air-water-surfactant systems, the calculation of the $\frac{\mathrm{k}_{\mathrm{L}}}{\mathrm{d}_{\mathrm{B}}}$ ratio from the measured $\mathrm{k}_{\mathrm{L}} \mathrm{a}_{\mathrm{L}}$ and $\varepsilon_{\mathrm{g}}$ is illustrated in Fig. 13. As shown in Fig.13, the plot of $\mathrm{k}_{\mathrm{L}} \mathrm{a}_{\mathrm{L}}$ against $\frac{6 \varepsilon_{\mathrm{g}}}{\left(1-\varepsilon_{\mathrm{g}}\right)}$ is nearly linear until a superficial gas velocity of $4.90 \mathrm{~cm} \cdot \mathrm{s}^{-1}$ and for a value of $\frac{6 \varepsilon_{\mathrm{g}}}{\left(1-\varepsilon_{\mathrm{g}}\right)}$ equals to 1.4, which matches with the transition flow regime. Then the $\frac{\mathrm{k}_{\mathrm{L}}}{\mathrm{d}_{\mathrm{B}}}$ ratio (corresponding to the slope of the curve) is constant and has a value of around $0.063 \mathrm{~s}^{-1}$. The values of $\frac{k_{L}}{d_{B}}$ for each liquid phase have been summarized in Table 4 . In the presence of surfactants, the $\frac{\mathrm{k}_{\mathrm{L}}}{\mathrm{d}_{\mathrm{B}}}$ ratio becomes lower compared to that in tap water and it is even lower for the ester solutions than for the amine solutions. Concerning the ester aqueous solutions, data from image analysis highlight that the mean bubble size is smaller than in tap water at low ester content ( $5 \mathrm{ppm}$ ), but also that the mean bubble diameter becomes higher and the bubble size distribution wider than in tap water when ester concentration increases, based on the evolution of the standard deviation and the mean bubble size in Table 5, respectively. For the ester, the comparison to tap water in Table 4 and Table 5 confirms, first, that the decrease in $\frac{\mathrm{k}_{\mathrm{L}}}{\mathrm{d}_{\mathrm{B}}}$ ratio against that of tap water is due to sharp decrease in $\mathrm{k}_{\mathrm{L}}$ at low ester concentration, and then, that this decrease is enhanced by an increase in bubble size at higher ester content. Conversely, for the cationic 
amine aqueous solutions, bubble diameter is nearly independent from the amine content and always smaller than in tap water (Table 5), which should lead to an enhancement in the $\frac{\mathrm{k}_{\mathrm{L}}}{\mathrm{d}_{\mathrm{B}}}$ ratio; but it is not the case and this trend proves a sharp decrease in $\mathrm{k}_{\mathrm{L}}$. The strong decrease in $\mathrm{k}_{\mathrm{L}}$ observed with both collectors can be attributed to the resulting adsorbed layer which induces a strong additional interfacial resistance to gas-liquid mass transfer by rigidifying the air-water interface.

\section{Conclusion}

This paper experimentally investigates the effects of the liquid surface tension, by using organic collectors as surface-active agents, on hydrodynamics (gas hold-up and flow regimes) and mass transfer $\left(\mathrm{k}_{\mathrm{L}} \mathrm{a}_{\mathrm{L}}\right)$ within a two-phase bubble column. The prominent results are outlined as follows:

- The addition of ester liquid leads to a decrease in gas hold-up due to primary bubble coalescence phenomena. Meanwhile, the gas hold-up has been shown to increase for amine aqueous solutions at superficial gas velocity higher than $7.24 \mathrm{~cm} \cdot \mathrm{s}^{-1}$ because of foam formation.

- Spectral analysis reveals that homogeneous flow prevailed until $\mathrm{U}_{\mathrm{g}} \leq 4.4 \mathrm{~cm} . \mathrm{s}^{-1}$ and was depicted by a peak at $0.1 \mathrm{~Hz}$ in the PSD. For ester aqueous solutions, a dominant peak at a frequency of about $5.8 \mathrm{~Hz}$ emerged, which indicated the formation of large bubbles even at low superficial gas velocity.

- The gas-liquid mass transfer was shown to decrease dramatically with collector addition due to surface tension decrease. Taking into account that, the apparent decrease in $\mathrm{k}_{\mathrm{L}} \mathrm{a}_{\mathrm{L}}$ can be explained by a strong decrease in $\mathrm{k}_{\mathrm{L}}$ values due to the presence of surfactant, which has been proved by the study of the $\frac{k_{L}}{d_{B}}$ ratio and the bubble size diameter, but this effect is reinforced in the case of the ester solutions by an increase in bubble size when ester concentration is increased.

It can be said that the present work is only a preliminary study focusing on the gas-liquid flow in flotation wastewaters treatment, but it however provides significant information on the possible specific effect of remnant additive residues at the bubble interface in subsequent treatments involving bubbly two-phase flows. So, the perspectives include, first, the experimental analysis of gas-liquid-solid flow by adding solid particles on the one hand, and 
the modeling of gas-liquid and gas-liquid-solid flows by tools such as Computational Fluid Dynamics (CFD) on the other hand.

\section{Nomenclature}

Roman letters

$\mathrm{a}_{\mathrm{L}} \quad$ interfacial area (per volume of liquid) $\left[\mathrm{m}^{-1}\right]$

$\mathrm{C}_{0} \quad$ initial dissolved oxygen concentration $\left[\mathrm{mg} . \mathrm{L}^{-1}\right]$

$\mathrm{C}_{\mathrm{t}} \quad$ instantaneous dissolved oxygen concentration $\left[\mathrm{mg} . \mathrm{L}^{-1}\right]$

$\mathrm{C}_{\mathrm{s}} \quad$ dissolved oxygen concentration at saturation [mg. $\left.\mathrm{L}^{-1}\right]$

$\mathrm{C}_{1} \quad$ parameter in Akita and Yoshida [54] correlation [dimensionless]

$\mathrm{d}_{\mathrm{c}} \quad$ column diameter $[\mathrm{cm}]$

$\mathrm{d}_{0} \quad$ sparger hole diameter $[\mathrm{cm}]$

$\mathrm{d}_{\mathrm{B}} \quad$ bubble diameter $[\mathrm{m}]$

$\mathrm{f}_{\mathrm{m}} \quad$ average frequency $[\mathrm{Hz}]$

g gravity constant $\left[\mathrm{m} . \mathrm{s}^{-2}\right]$

$\mathrm{H}_{\mathrm{c}} \quad$ column height $[\mathrm{cm}]$

$\mathrm{H}_{0} \quad$ clear liquid height [m]

$\mathrm{j}_{\mathrm{gl}} \quad$ drift flux $\left[\mathrm{m} \cdot \mathrm{s}^{-1}\right]$

$\mathrm{k}_{\mathrm{L}} \quad$ liquid mass transfer coefficient $\left[\mathrm{m} . \mathrm{s}^{-1}\right]$

$\mathrm{k}_{\mathrm{L}} \mathrm{a}_{\mathrm{L}} \quad$ volumetric liquid mass transfer coefficient $\left[\mathrm{s}^{-1}\right]$

$\mathrm{P} \quad$ Pressure $[\mathrm{Pa}]$

$\mathrm{P}_{\mathrm{xx}}(\mathrm{f})$ average power spectral density $\left[\mathrm{Pa}^{2} . \mathrm{s}\right]$

$\mathrm{U}_{\mathrm{g}} \quad$ superficial gas velocity $\left[\mathrm{cm} . \mathrm{s}^{-1}\right]$

$\mathrm{U}_{\text {swarm }} \quad$ superficial gas velocity $\left[\mathrm{m} . \mathrm{s}^{-1}\right]$ 
Greek letters

$\Delta \mathrm{P} \quad$ differential pressure $[\mathrm{Pa}]$

$\Delta \mathrm{H} \quad$ height difference $[\mathrm{m}]$

$\varepsilon_{\mathrm{g}} \quad$ gas hold-up [dimensionless]

$\rho_{\mathrm{L}} \quad$ liquid density $\left[\mathrm{g} . \mathrm{cm}^{-3}\right]$

$v_{\mathrm{L}} \quad$ bubble terminal velocity $\left[\mathrm{m}^{2} \cdot \mathrm{s}^{-1}\right]$

$\rho_{\mathrm{g}} \quad$ gas density $\left[\mathrm{g} . \mathrm{cm}^{-3}\right]$

$\mu_{\mathrm{L}} \quad$ liquid viscosity [Pa.s]

$\sigma_{\mathrm{L}} \quad$ liquid surface tension $\left[\mathrm{mN} \cdot \mathrm{m}^{-1}\right]$

Subscripts

L liquid phase

g gas phase

\section{Acknowledgment}

The authors would like to acknowledge the financial support provided by the Moroccan OCP group (Office Chérifien des Phosphates - Maroc) through project: ACD GOU-01/2017. The authors are also grateful to the steering committee of the project and OCP Foundation. 


\section{References}

[1] F. Gallucci, A. Pacheco Tanaka, M. van Sint Annaland, Ethanol Reforming in Thermally Coupled, Fluidized-Bed, Bubble Column, and Membrane Reactors, in: Ethanol, Elsevier, 2019: pp. 355-382. https://doi.org/10.1016/B978-0-12-811458-2.00014-6.

[2] J. Chalupa, O. Pocik, M. Halecky, E. Kozliak, Thermophilic waste air treatment of an airborne ethyl acetate/toluene mixture in a bubble column reactor: Stability towards temperature changes, Journal of Hazardous Materials. 384 (2020) 120744. https://doi.org/10.1016/j.jhazmat.2019.120744.

[3] Y.T. Shah, B.G. Kelkar, S.P. Godbole, W.-D. Deckwer, Design parameters estimations for bubble column reactors, AIChE Journal. $28 \quad$ (1982) 353-379. https://doi.org/10.1002/aic.690280302.

[4] G. Besagni, F. Inzoli, The effect of liquid phase properties on bubble column fluid dynamics: Gas holdup, flow regime transition, bubble size distributions and shapes, interfacial areas and foaming phenomena, Chemical Engineering Science. 170 (2017) 270-296. https://doi.org/10.1016/j.ces.2017.03.043.

[5] M. Shiea, N. Mostoufi, R. Sotudeh-Gharebagh, Comprehensive study of regime transitions throughout a bubble column using resistivity probe, Chemical Engineering Science. 100 (2013) 15-22. https://doi.org/10.1016/j.ces.2013.01.047.

[6] G. Besagni, F. Inzoli, G. De Guido, L.A. Pellegrini, The dual effect of viscosity on bubble column hydrodynamics, Chemical Engineering Science. 158 (2017) 509-538. https://doi.org/10.1016/j.ces.2016.11.003.

[7] A. Esmaeili, C. Guy, J. Chaouki, The effects of liquid phase rheology on the hydrodynamics of a gas-liquid bubble column reactor, Chemical Engineering Science. 129 (2015) 193-207. https://doi.org/10.1016/j.ces.2015.01.071.

[8] B.G. Kelkar, S.P. Godbole, M.F. Honath, Y.T. Shah, N.L. Carr, W.-D. Deckwer, Effect of addition of alcohols on gas holdup and backmixing in bubble columns, AIChE J. 29 (1983) 361-369. https://doi.org/10.1002/aic.690290303.

[9] J. Lu, C.M. Corvalan, Y.M.J. Chew, J.-Y. Huang, Coalescence of small bubbles with surfactants, Chemical Engineering Science. $196 \quad$ (2019) 493-500. https://doi.org/10.1016/j.ces.2018.11.002.

[10] E. Camarasa, C. Vial, S. Poncin, G. Wild, N. Midoux, J. Bouillard, Influence of coalescence behaviour of the liquid and of gas sparging on hydrodynamics and bubble 
characteristics in a bubble column, Chemical Engineering and Processing: Process Intensification. 38 (1999) 329-344. https://doi.org/10.1016/S0255-2701(99)00024-0.

[11] B. Gourich, C. Vial, A.H. Essadki, F. Allam, M. Belhaj Soulami, M. Ziyad, Identification of flow regimes and transition points in a bubble column through analysis of differential pressure signal-Influence of the coalescence behavior of the liquid phase, Chemical Engineering and Processing: Process Intensification. 45 (2006) 214-223. https://doi.org/10.1016/j.cep.2005.09.002.

[12] E. Delnoij, J.A.M. Kuipers, Measurement of gas-liquid two-phase fow in bubble columns using ensemble correlation PIV, Chemical Engineering Science. (2000) 11.

[13] D. Toye, E. Fransolet, D. Simon, M. Crine, G. L’Homme, P. Marchot, Possibilities and Limits of Application of Electrical Resistance Tomography in Hydrodynamics of Bubble Columns, The Canadian Journal of Chemical Engineering. 83 (2008) 4-10. https://doi.org/10.1002/cjce.5450830103.

[14] E. Olmos, C. Gentric, S. Poncin, N. Midoux, Description of flow regime transitions in bubble columns via laser Doppler anemometry signals processing, Chemical Engineering Science. 58 (2003) 1731-1742. https://doi.org/10.1016/S0009-2509(03)00002-2.

[15] A. Sheikhi, R. Sotudeh-Gharebagh, R. Zarghami, N. Mostoufi, M. Alfi, Understanding bubble hydrodynamics in bubble columns, Experimental Thermal and Fluid Science. 45 (2013) 63-74. https://doi.org/10.1016/j.expthermflusci.2012.10.008.

[16] W. Chen, A. Tsutsumi, K. Otawara, Y. Shigaki, Local Bubble Dynamics and Macroscopic Flow Structure in Bubble Columns with Different Scales, The Canadian Journal of Chemical Engineering. 81 (2003) 1139-1148. https://doi.org/10.1002/cjce.5450810603.

[17] C. Vial, E. Camarasa, S. Poncin, G. Wild, N. Midoux, J. Bouillard, Study of hydrodynamic behaviour in bubble columns and external loop airlift reactors through analysis of pressure fluctuations, Chemical Engineering Science. (2000) 17.

[18] P. Blazy, E.-A. Jdid, Flottation - Mécanismes et réactifs, Techniques de l’Ingénieur. J3350 V1 (2000) 1-25.

[19] S.M. Bulatovic, Handbook of flotation reagents: chemistry, theory and practice, 1st ed, Elsevier, Amsterdam; Boston, 2007.

[20] G. Liu, X. Yang, H. Zhong, Molecular design of flotation collectors: A recent progress, Advances in Colloid and Interface Science. 246 (2017) 181-195. https://doi.org/10.1016/j.cis.2017.05.008.

[21] Y. Ruan, D. He, R. Chi, Review on Beneficiation Techniques and Reagents Used for Phosphate Ores, Minerals. 9 (2019) 1-18. https://doi.org/10.3390/min9040253. 
[22] H. Sis, S. Chander, Reagents used in the flotation of phosphate ores: a critical review, Minerals Engineering. 16 (2003) 577-585. https://doi.org/10.1016/S08926875(03)00131-6.

[23] H.S. Al-Zoubi, S.S. Al-Thyabat, Treatment of a Jordanian Phosphate Mine Wastewater by Hybrid Dissolved Air Flotation and Nanofiltration, Mine Water Environ. 31 (2012) 214-224. https://doi.org/10.1007/s10230-012-0197-1.

[24] N. Deo, K.A. Natarajan, Biological removal of some flotation collector reagents from aqueous solutions and mineral surfaces, Minerals Engineering. 11 (1998) 717-738. https://doi.org/10.1016/S0892-6875(98)00058-2.

[25] E. Chockalingam, S. Subramanian, K.A. Natarajan, Studies on biodegradation of organic flotation collectors using Bacillus polymyxa, Hydrometallurgy. 71 (2003) 249-256. https://doi.org/10.1016/S0304-386X(03)00163-4.

[26] S. Chen, W. Gong, G. Mei, Q. Zhou, C. Bai, N. Xu, Primary biodegradation of sulfide mineral flotation collectors, Minerals Engineering. 24 (2011) 953-955. https://doi.org/10.1016/j.mineng.2011.01.003.

[27] Y. Dong, H. Lin, Q. Liu, H. Huo, Treatment of flotation wastewater using biological activated carbon, J. Cent. South Univ. 21 (2014) 3580-3587. https://doi.org/10.1007/s11771-014-2339-z.

[28] X. Jia, W. Hu, X. Yuan, K. Yu, Effect of surfactant type on interfacial area and liquid mass transfer for $\mathrm{CO}_{2}$ absorption in a bubble column, Chinese Journal of Chemical Engineering. 23 (2015) 476-481. https://doi.org/10.1016/j.cjche.2014.11.027.

[29] J.M.T. Vasconcelos, J.M.L. Rodrigues, S.C.P. Orvalho, S.S. Alves, R.L. Mendes, A. Reis, Effect of contaminants on mass transfer coefficients in bubble column and airlift contactors, Chemical Engineering Science. 58 (2003) 1431-1440. https://doi.org/10.1016/S0009-2509(02)00675-9.

[30] M. Zedníková, S. Orvalho, M. Fialová, M. Ruzicka, Measurement of Volumetric Mass Transfer Coefficient in Bubble Columns, ChemEngineering. 2 (2018) 19. https://doi.org/10.3390/chemengineering2020019.

[31] S.S. Alves, S.P. Orvalho, J.M.T. Vasconcelos, Effect of bubble contamination on rise velocity and mass transfer, Chemical Engineering Science. 60 (2005) 1-9. https://doi.org/10.1016/j.ces.2004.07.053.

[32] K. Loubière, G. Hébrard, Influence of liquid surface tension (surfactants) on bubble formation at rigid and flexible orifices, Chemical Engineering and Processing: Process Intensification. 43 (2004) 1361-1369. https://doi.org/10.1016/j.cep.2004.03.009. 
[33] R. Sardeing, P. Painmanakul, G. Hébrard, Effect of surfactants on liquid-side mass transfer coefficients in gas-liquid systems: A first step to modeling, Chemical Engineering Science. 61 (2006) 6249-6260. https://doi.org/10.1016/j.ces.2006.05.051.

[34] M. Jamnongwong, K. Loubière, N. Dietrich, G. Hébrard, Experimental study of oxygen diffusion coefficients in clean water containing salt, glucose or surfactant: Consequences on the liquid-side mass transfer coefficients, Chemical Engineering Journal. 165 (2010) 758-768. https://doi.org/10.1016/j.cej.2010.09.040.

[35] C. Vial, S. Poncin, G. Wild, N. Midoux, A simple method for regime identification and flow characterisation in bubble columns and airlift reactors, Chemical Engineering and Processing: Process Intensification. 40 (2001) 135-151. https://doi.org/10.1016/S02552701(00)00133-1.

[36] W. Tchowa Medjiade, A. Rosenbaum Alvaro, A. Schumpe, Flow regime transitions in a bubble column, Chemical Engineering Science. $170 \quad$ (2017) 263-269. https://doi.org/10.1016/j.ces.2017.04.010.

[37] G. Besagni, L. Gallazzini, F. Inzoli, On the scale-up criteria for bubble columns, Petroleum. 5 (2019) 114-122. https://doi.org/10.1016/j.petlm.2017.12.005.

[38] K. Koide, S. Yamazoe, S. Harada, Effects of surface-active substances on gas holdup and gas-liquid mass transfer in bubble column., J. Chem. Eng. Japan / JCEJ. 18 (1985) 287292. https://doi.org/10.1252/jcej.18.287.

[39] H. Yagi, F. Yoshida, Oxygen absorption in fermenters: Effects of surfactants, antifoaming agents, and sterilized cells, 52 (1974) 905-916.

[40] A. Kumar, T.E. Degaleesan, G.S. Laddha, H.E. Hoelscher, Bubble swarm characteristics in bubble columns, Can. J. Chem. Eng. 54 (1976) 503-508. https://doi.org/10.1002/cjce.5450540525.

[41] H. Hikita, H. Kikukawa, Liquid-phase mixing in bubble columns: Effect of liquid properties, The Chemical Engineering Journal. 8 (1974) 191-197. https://doi.org/10.1016/0300-9467(74)85024-0.

[42] G.A. Hughmark, Holdup and Mass Transfer in Bubble Columns, Ind. Eng. Chem. Proc. Des. Dev. 6 (1967) 218-220. https://doi.org/10.1021/i260022a011.

[43] I.G. Reilly, D.S. Scott, T. De Bruijn, A. Jain, J. Piskorz, A correlation for gas holdup in turbulent coalescing bubble columns, Can. J. Chem. Eng. 64 (1986) 705-717. https://doi.org/10.1002/cjce.5450640501. 
[44] L. Gemello, C. Plais, F. Augier, A. Cloupet, D.L. Marchisio, Hydrodynamics and bubble size in bubble columns: Effects of contaminants and spargers, Chemical Engineering Science. 184 (2018) 93-102. https://doi.org/10.1016/j.ces.2018.03.043.

[45] N. Zuber, J.A. Findlay, Average Volumetric Concentration in Two-Phase Flow Systems, J. Heat Transfer. 87 (1965) 453-468. https://doi.org/10.1115/1.3689137.

[46] G.B. Wallis, One-dimensional two-phase flow, McGraw-Hill, New York, NY, 1969.

[47] J. Drahoš, J. Zahradník, M. Punčochář, M. Fialová, F. Bradka, Effect of operating conditions on the characteristics of pressure fluctuations in a bubble column, Chemical Engineering and Processing: Process Intensification. 29 (1991) 107-115. https://doi.org/10.1016/0255-2701(91)87019-Y.

[48] X. Dong, Z. Liu, F. Liu, Z. Li, W. Wei, X. Wang, X. Xu, Effect of liquid phase rheology and gas-liquid interface property on mass transfer characteristics in bubble columns, Chemical Engineering Research and Design. 142 (2019) 25-33. https://doi.org/10.1016/j.cherd.2018.11.035.

[49] W.J. Nock, S. Heaven, C.J. Banks, Mass transfer and gas-liquid interface properties of single CO2 bubbles rising in tap water, Chemical Engineering Science. 140 (2016) 171178. https://doi.org/10.1016/j.ces.2015.10.001.

[50] C.O. Vandu, R. Krishna, Influence of scale on the volumetric mass transfer coefficients in bubble columns, Chemical Engineering and Processing: Process Intensification. 43 (2004) 575-579. https://doi.org/10.1016/S0255-2701(03)00015-1.

[51] B. Gourich, Ch. Vial, N. El Azher, M. Belhaj Soulami, M. Ziyad, Influence of hydrodynamics and probe response on oxygen mass transfer measurements in a high aspect ratio bubble column reactor: Effect of the coalescence behaviour of the liquid phase, Biochemical Engineering Journal. $39 \quad$ (2008) 1-14. https://doi.org/10.1016/j.bej.2007.08.011.

[52] S. Shioya, I.J. Dunn, A Dynamic oxygen transfer coefficient measurement method for column reactors, Chemical Engineering Science. 33 (1978) 1529-1534. https://doi.org/10.1016/0009-2509(78)85203-8.

[53] M.Y. Chisti, Airlift bioreactors, Elsevier Applied Science, London; New York, 1989.

[54] K. Akita, F. Yoshida, Gas Holdup and Volumetric Mass Transfer Coefficient in Bubble Columns. Effects of Liquid Properties, Ind. Eng. Chem. Proc. Des. Dev. 12 (1973) 76-80. https://doi.org/10.1021/i260045a015. 
[55] A. Schumpe, W.-D. Deckwer, Viscous media in tower bioreactors: Hydrodynamic characteristics and mass transfer properties, Bioprocess Engineering. 2 (1987) 79-94. https://doi.org/10.1007/BF00369528.

[56] S.P. Godbole, M.F. Honath, Y.T. Shah, Holdup structure in highly viscous Newtonian and non-Newtonian liquids in bubble columns, Chemical Engineering Communications. 16 (1982) 119-134. https://doi.org/10.1080/00986448208911090.

[57] Y. Kawase, M. Moo-Young, Theoretical prediction of gas hold-up in bubble columns with Newtonian and non-Newtonian fluids, Ind. Eng. Chem. Res. 26 (1987) 933-937. https://doi.org/10.1021/ie00065a014.

[58] Y. Kawase, S. Umeno, T. Kumagai, The prediction of gas hold-up in bubble column reactors: Newtonian and non-Newtonian fluids, The Chemical Engineering Journal. 50 (1992) 1-7. https://doi.org/10.1016/0300-9467(92)80001-Q.

[59] T.-J. Lin, R.-C. Juang, Y.-C. Chen, C.-C. Chen, Predictions of flow transitions in a bubble column by chaotic time series analysis of pressure fluctuation signals, Chemical Engineering Science. 56 (2001) 1057-1065. https://doi.org/10.1016/S00092509(00)00322-5.

[60] V.P. Chilekar, M.J.F. Warnier, J. van der Schaaf, B.F.M. Kuster, J.C. Schouten, J.R. van Ommen, Bubble size estimation in slurry bubble columns from pressure fluctuations, AIChE Journal. 51 (2005) 1924-1937. https://doi.org/10.1002/aic.10427. 


\section{Figure captions}

Fig. 1. Schematic of experimental setup.

Fig. 2. Gas hold-up versus superficial gas velocity for (a) air-tap water-amine, and (b) air-tap water-ester.

Fig. 3. Influence of the liquid phase properties on gas hold-up measurements (air-tap water, amine and ester aqueous solutions) (a); Overall gas hold-up versus surfactant concentrations for different superficial gas velocities: (b) tap water and amine aqueous solution, and (c) tap water and ester aqueous solution.

Fig. 4. Gas hold-up axial profiles at different superficial gas velocity.

Fig. 5. Comparison between predicted and experimental gas hold-up values for (a) tap waterair, (b) 50 ppm amine aqueous solution-air, and (c) 50 ppm ester aqueous solution-air (dash lines correspond to $\pm 30 \%$ error).

Fig. 6. Regime transition analysis: the swarm velocity and the drift flux plot.

Fig. 7. Example of bubbles using $30 \mathrm{ppm}$ of ester, and $\mathrm{U}_{\mathrm{g}}=2.53 \mathrm{~cm} \cdot \mathrm{s}^{-1}$.

Fig. 8. Power spectral density of the pressure time series for (a) tap water, (b) 50 ppm amine aqueous solution, and (c) 50 ppm ester aqueous solution at different superficial gas velocities.

Fig. 9. Average frequency of the spectrum versus superficial gas velocity for tap water and surfactant aqueous solutions.

Fig. 10. Temporal variation of dissolved oxygen curves in tap water and surfactant aqueous solutions.

Fig. 11. Volumetric mass transfer coefficient $\mathrm{k}_{\mathrm{L}} \mathrm{a}_{\mathrm{L}}$ versus the superficial gas velocity for tap water and surfactant aqueous solutions.

Fig. 12. Effect of the oxygen sensor position on the volumetric mass transfer coefficient $k_{L} a_{L}$ ((a) tap water-air, and (b) 5 ppm ester-tap water-air).

Fig. 13. Correlation of the measured $\mathrm{k}_{\mathrm{L}} \mathrm{a}_{\mathrm{L}}$ and gas hold-up $\varepsilon_{\mathrm{g}}$ according to Eq. (9). 


\section{Table captions}

Table 1 Hold-up correlations in literature.

Table $2 \mathrm{~A}$ few studies that used the pressure fluctuation methods for regime flow identification in bubble columns.

Table 3 Surface tension and apparent viscosity of the liquids at $25^{\circ} \mathrm{C}$.

Table 4 Comparison of $\mathrm{k}_{\mathrm{L}} / \mathrm{d}_{\mathrm{B}}$ ratio for tap water and surfactant aqueous solutions.

Table 5 Comparison bubble size estimation using image analysis at $\mathrm{U}_{\mathrm{g}}=1.2 \mathrm{~cm} / \mathrm{s}$. 


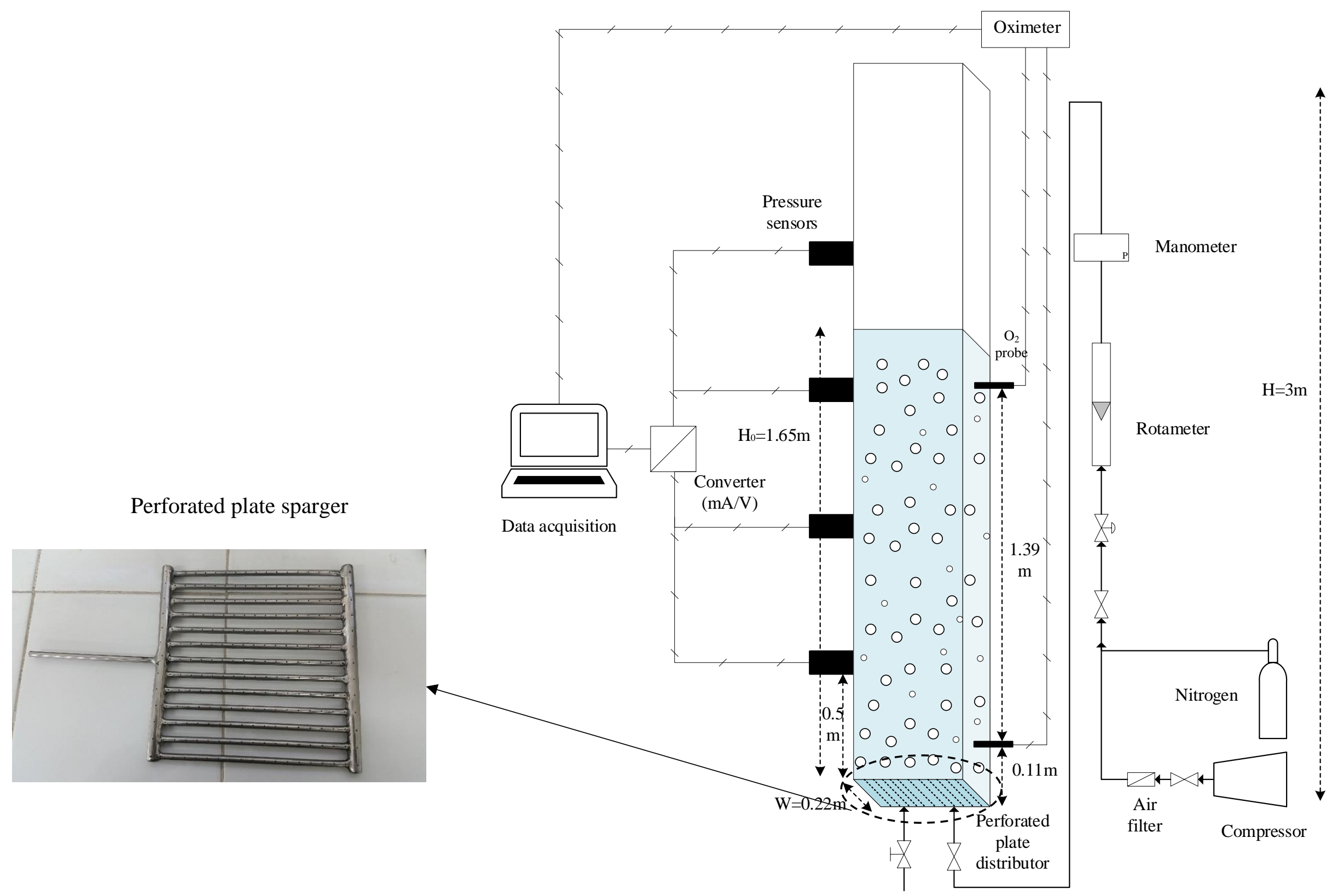

Fig. 1. Schematic of experimental setup. 


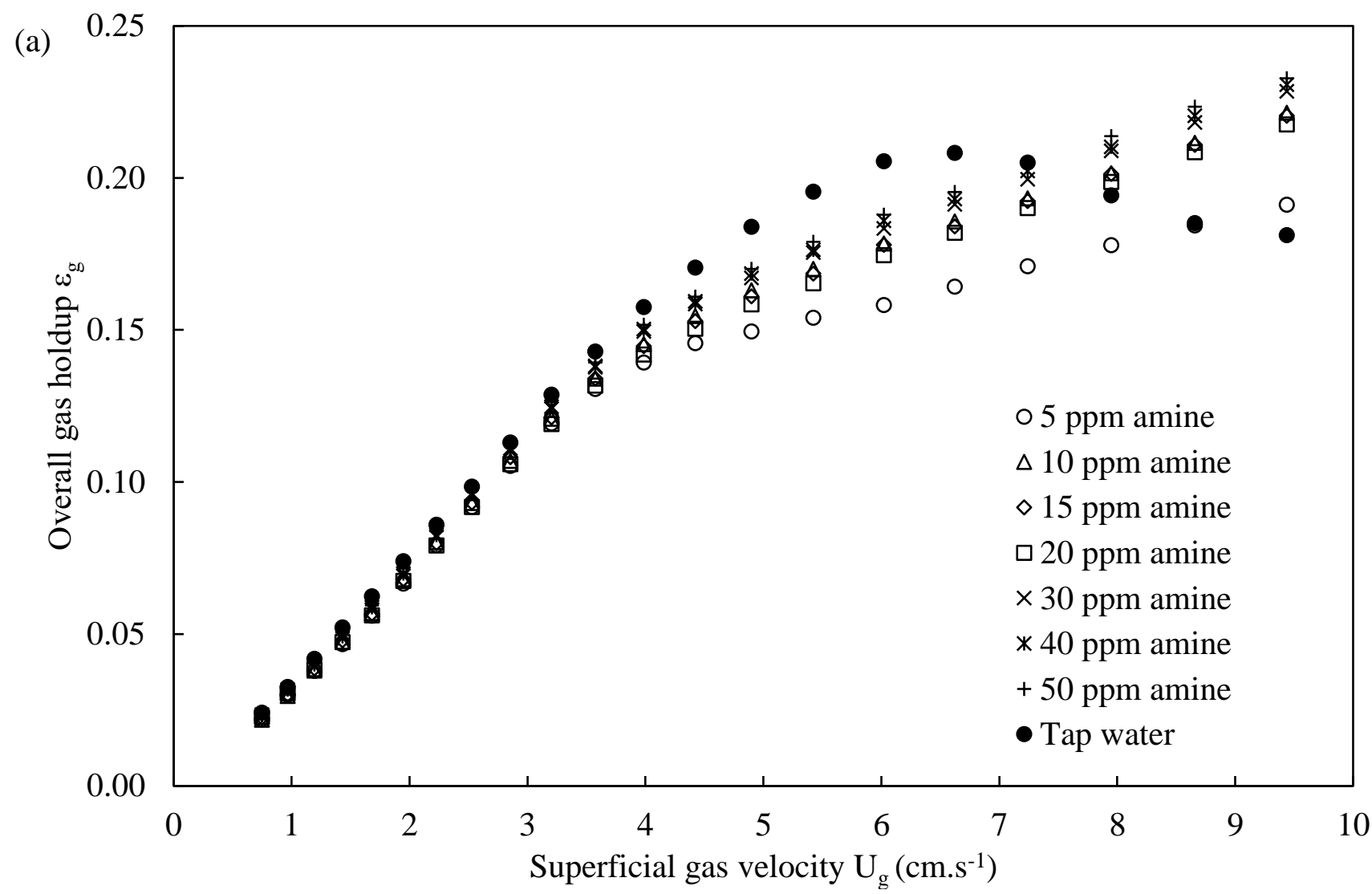

(b)

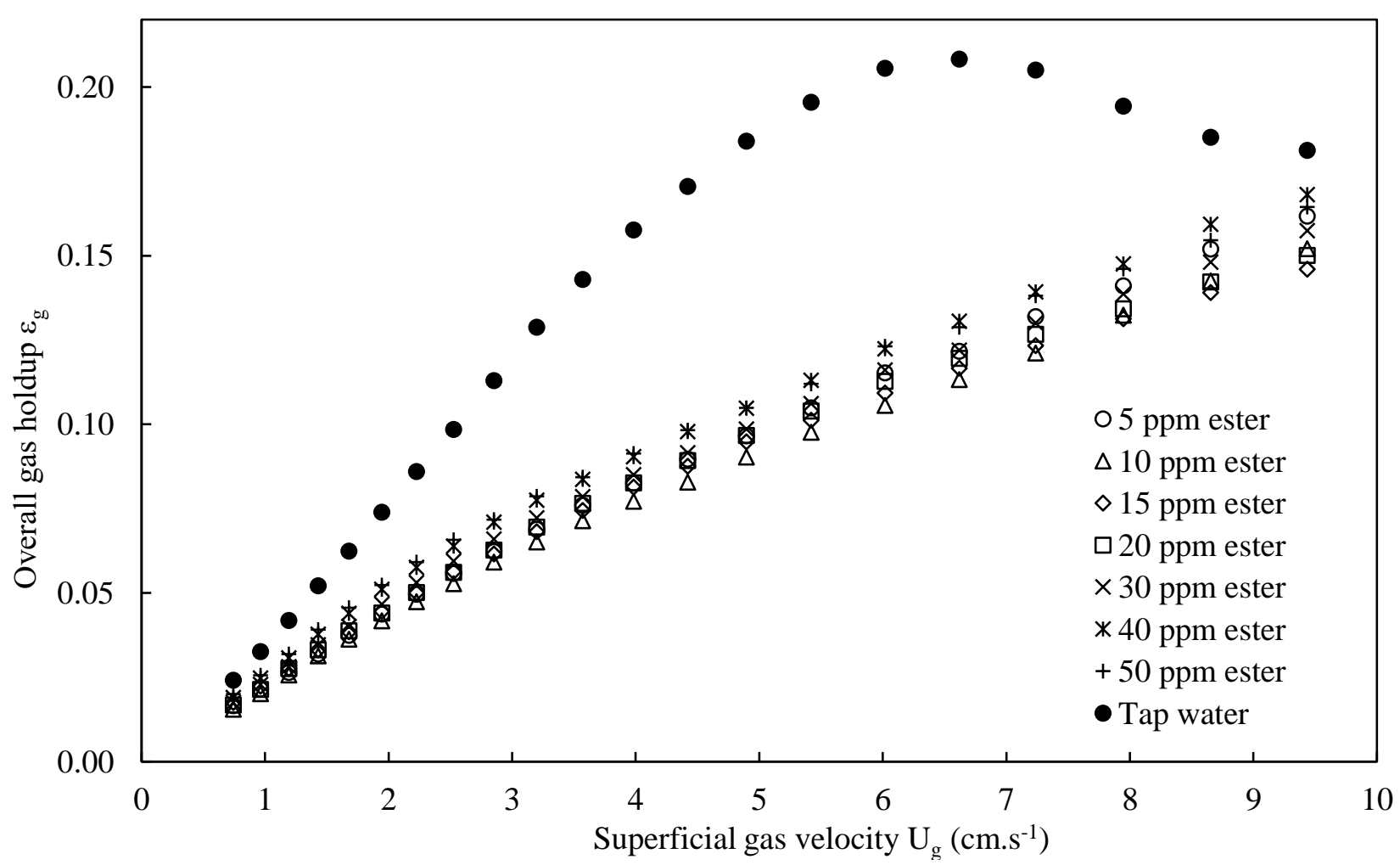

Fig. 2. Overall gas hold-up versus superficial gas velocity for (a) air-tap water-amine, and (b) air-tap water-ester. 
(a)

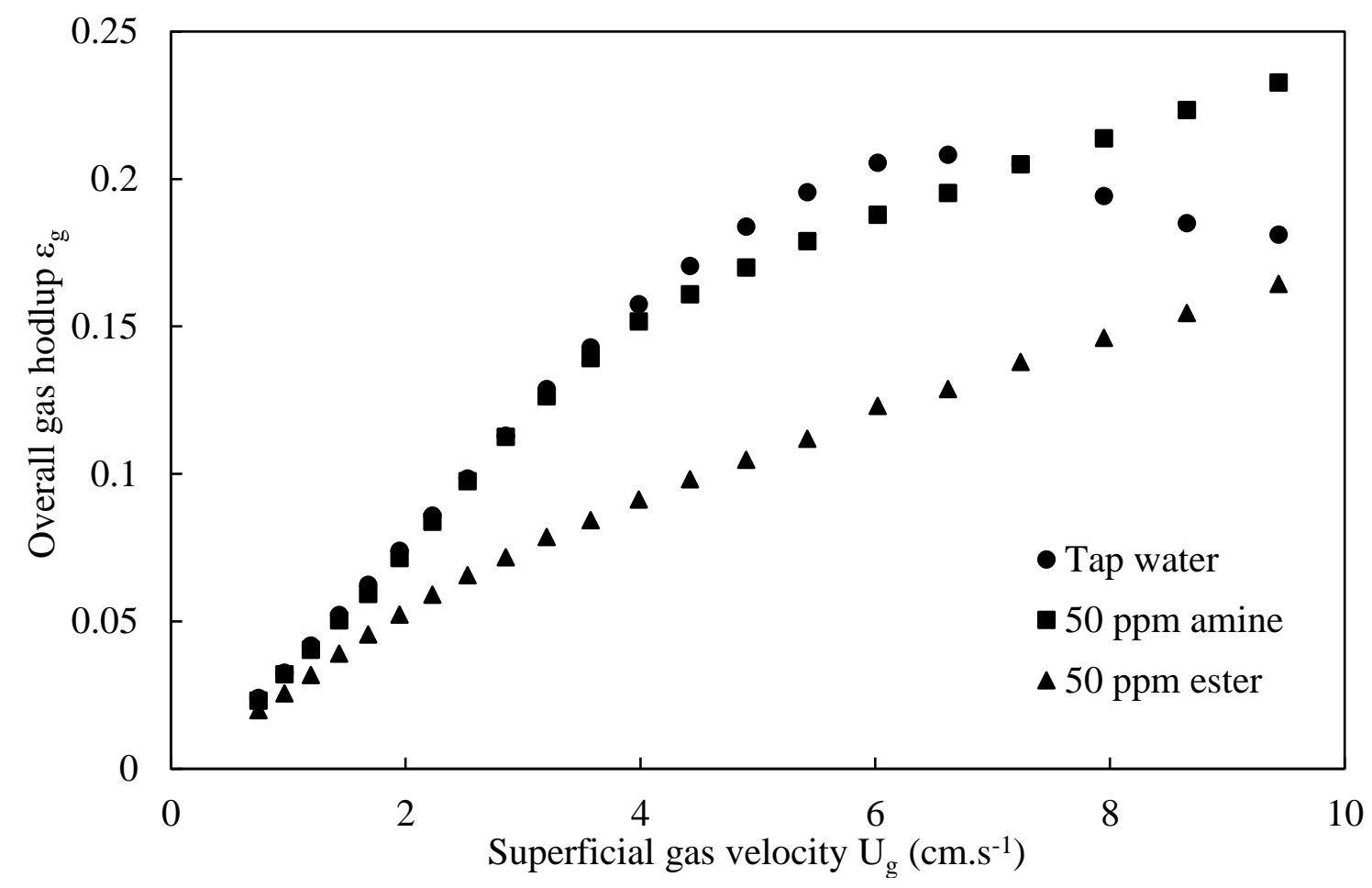

(b)

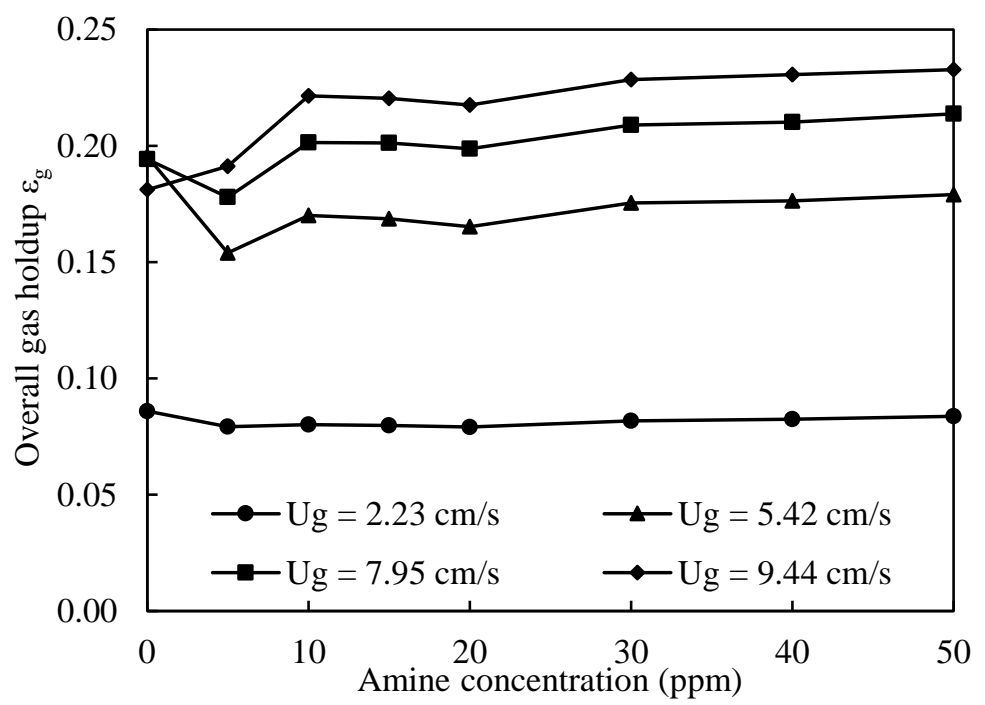

(c)

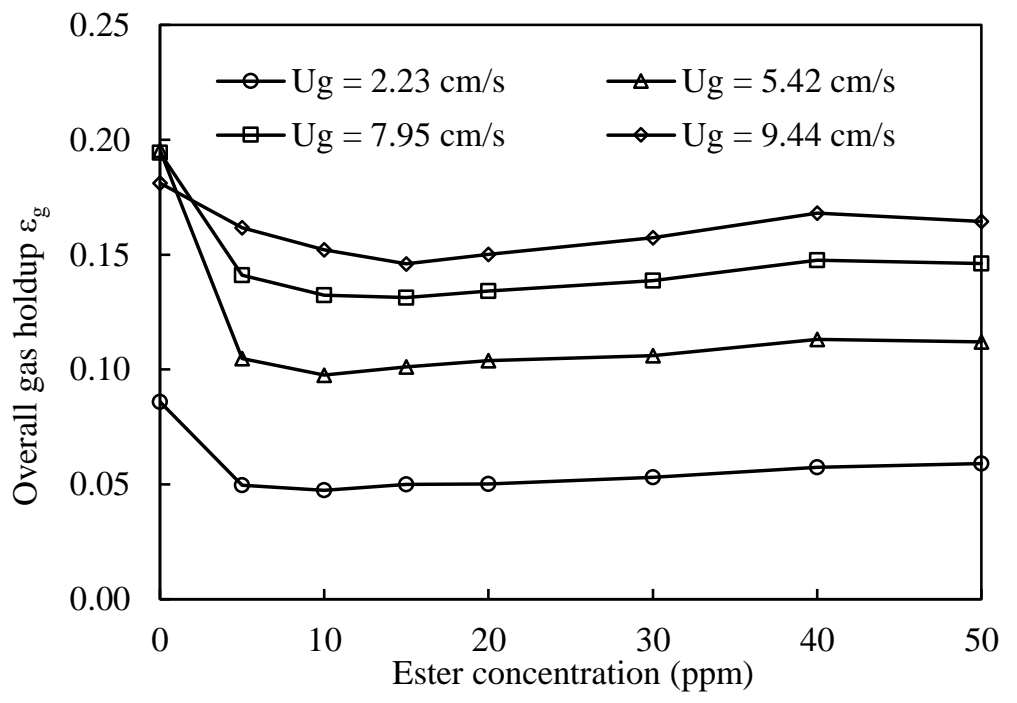

Fig. 3. Influence of the liquid phase properties on overall gas hold-up measurements (air-tap water, amine and ester aqueous solutions) (a); Overall gas hold-up versus surfactant concentrations for different superficial gas velocities: (b) tap water and amine aqueous solution, and (c) tap water and ester aqueous solution. 

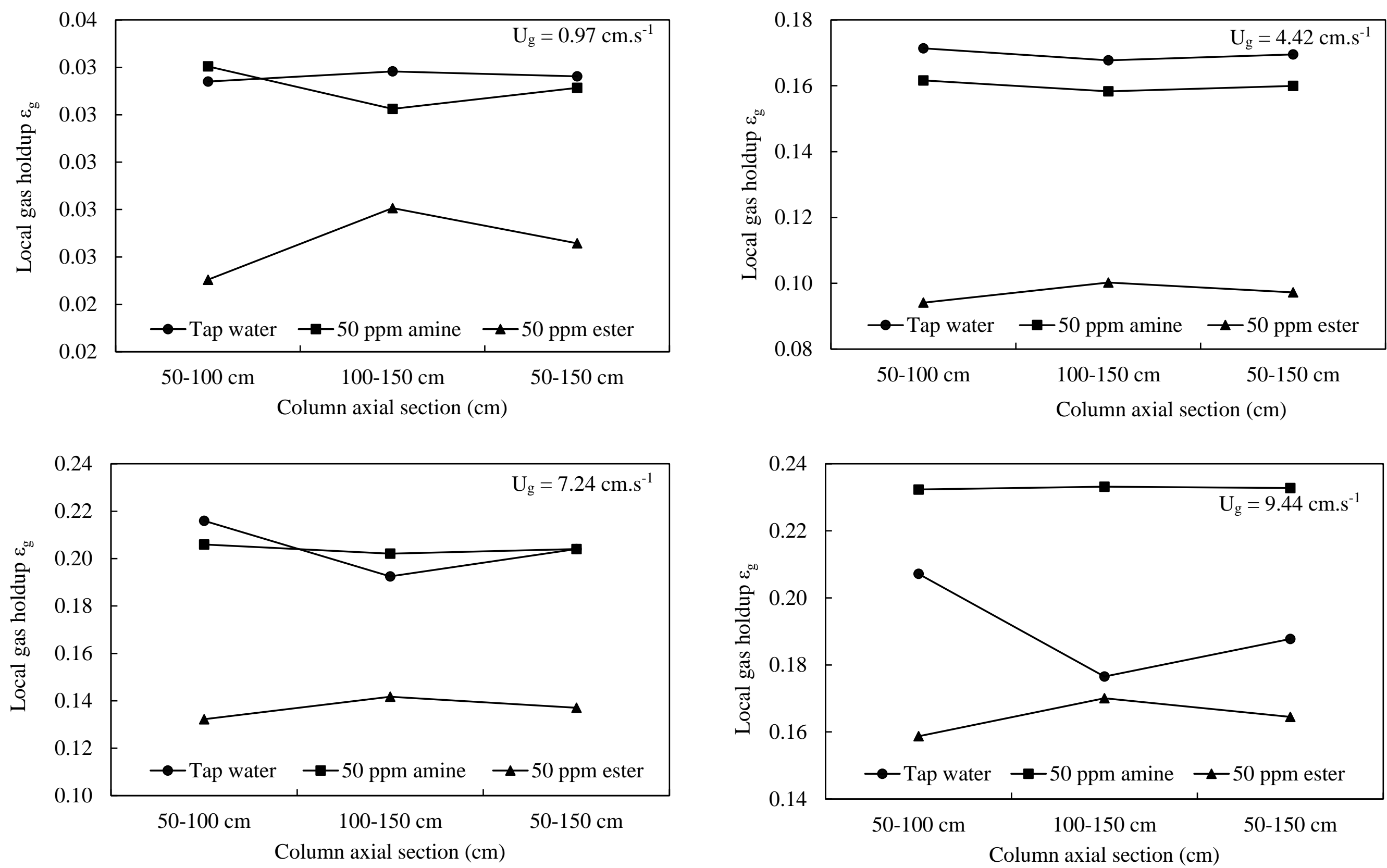

Fig. 4. Local gas holdup axial profiles at different superficial gas velocity. 
(a)

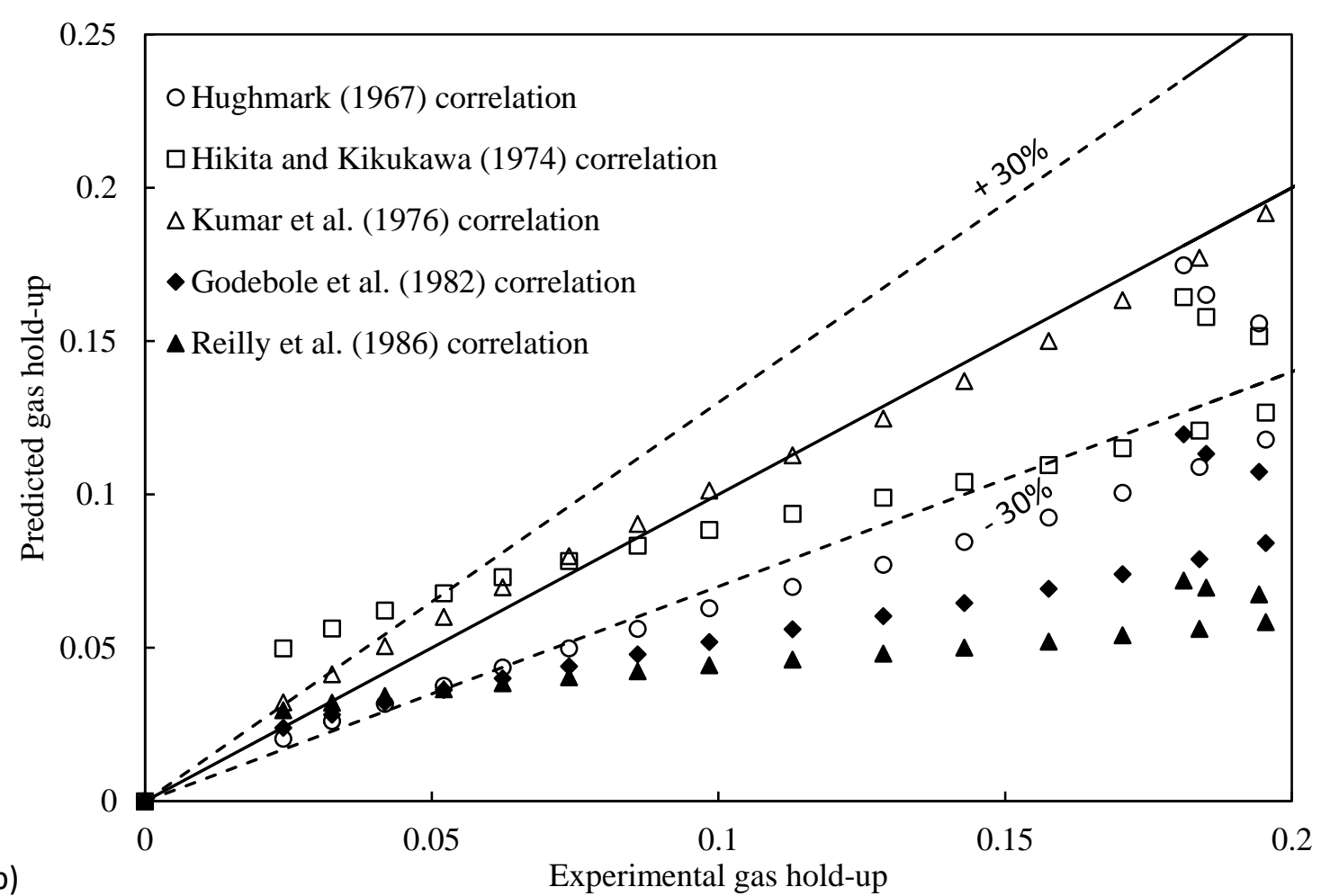

(b)

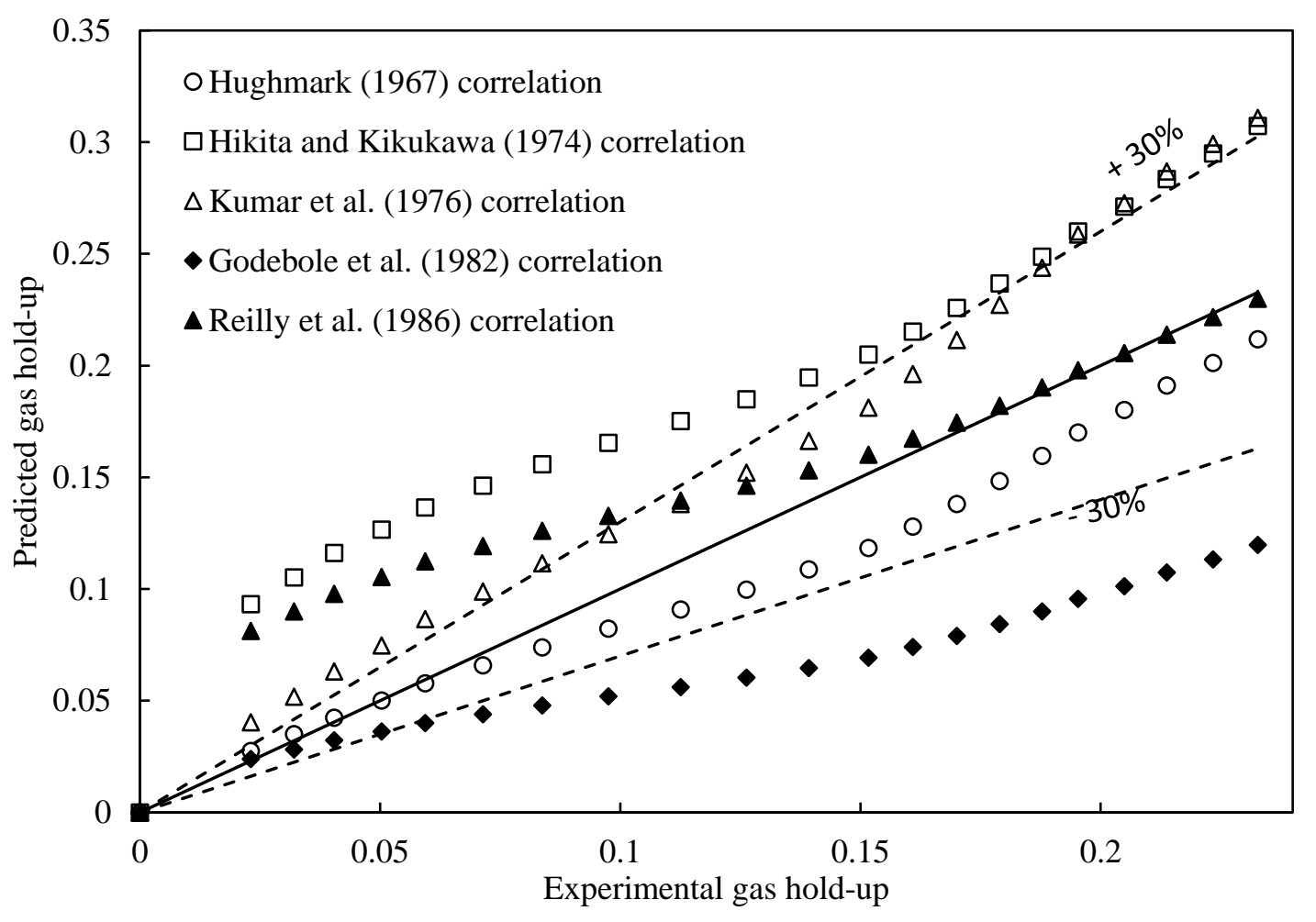




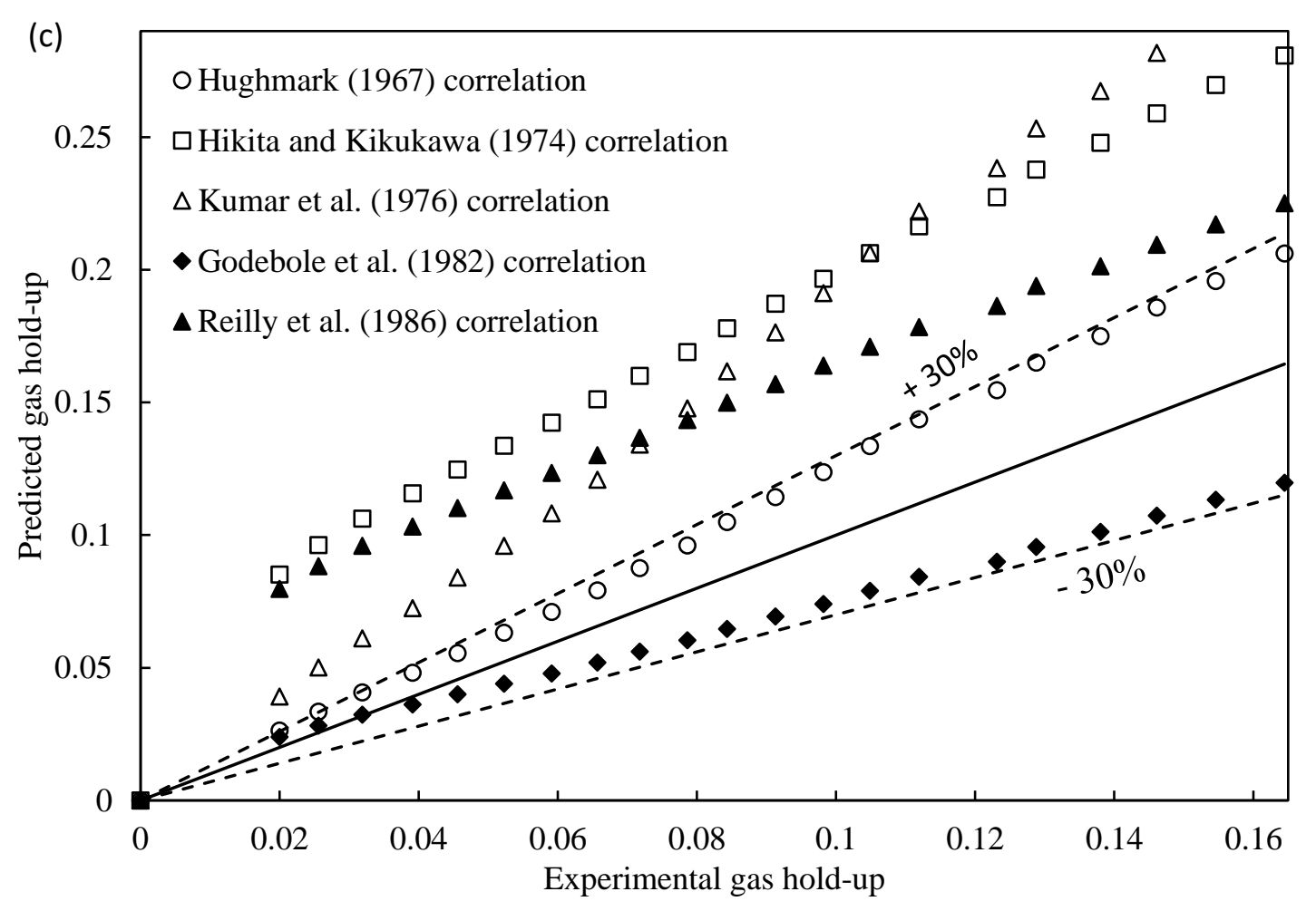

Fig. 5. Comparison between predicted and experimental gas hold-up values for (a) tap waterair, (b) 50 ppm amine aqueous solution-air, and (c) 50 ppm ester aqueous solution-air (dash lines correspond to $\pm 30 \%$ error).

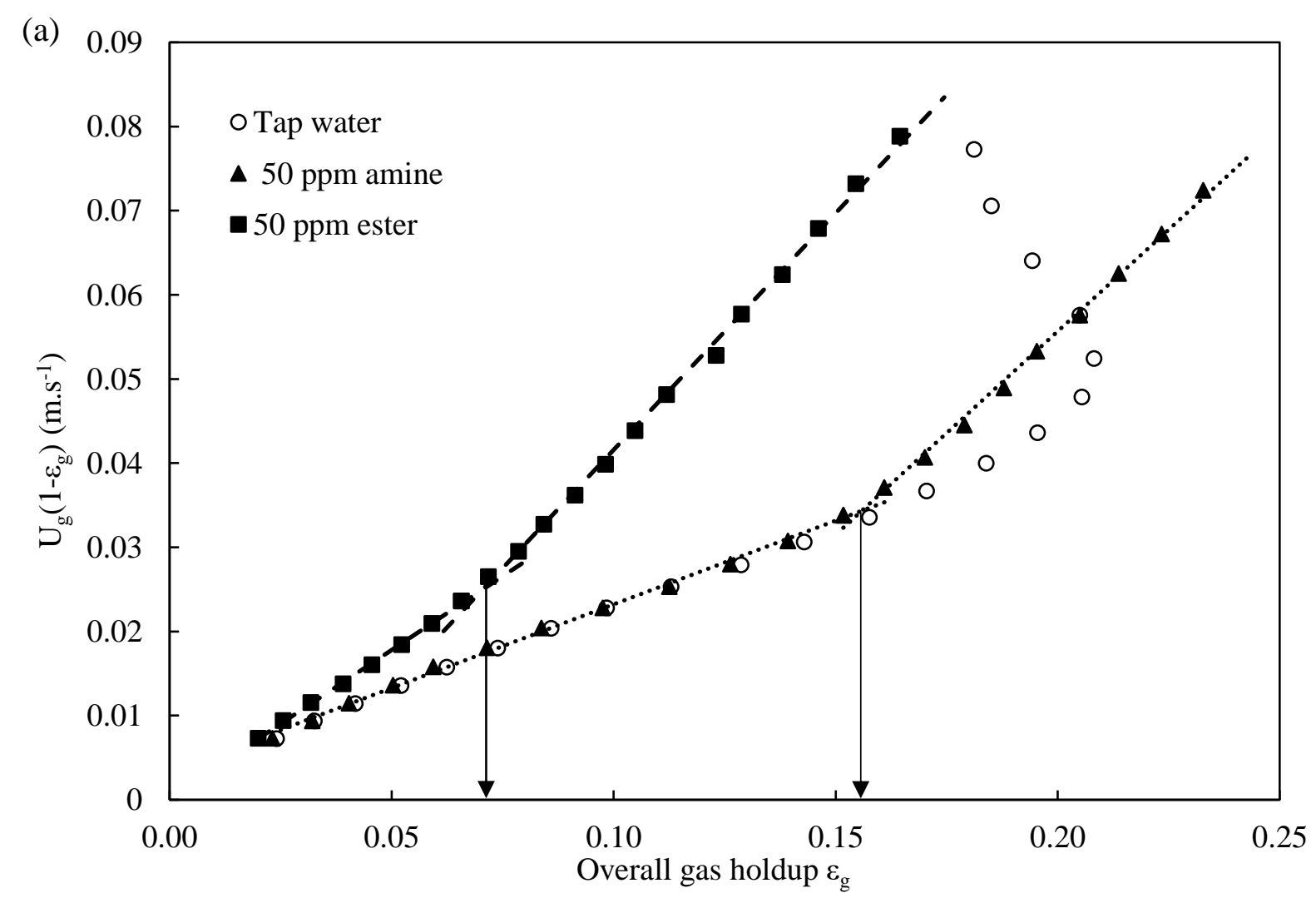


(b)

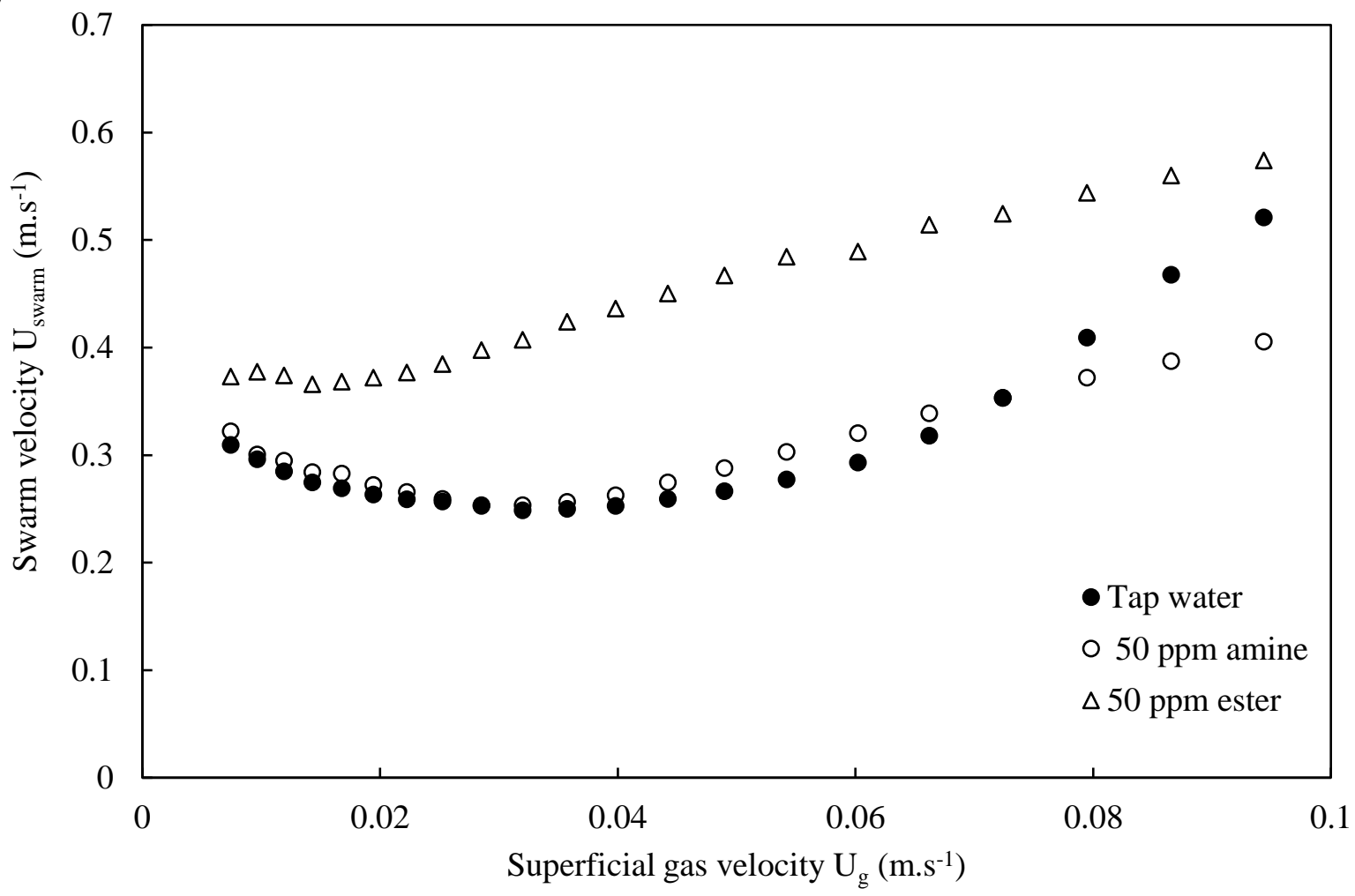

Fig. 6. Regime transition analysis: the swarm velocity (Eq. 7) and the drift flux plot.

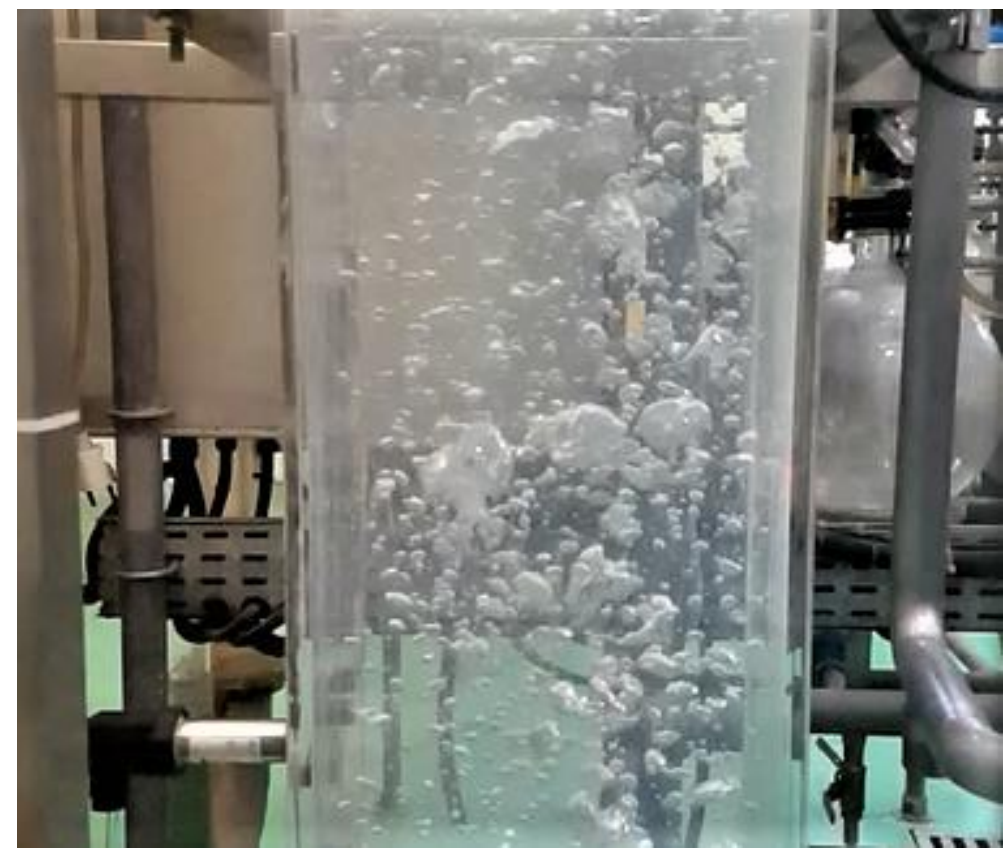

Fig. 7. Example of bubbles using $30 \mathrm{ppm}$ of ester, and $U_{\mathrm{g}}=2.53 \mathrm{~cm} \cdot \mathrm{s}^{-1}$. 

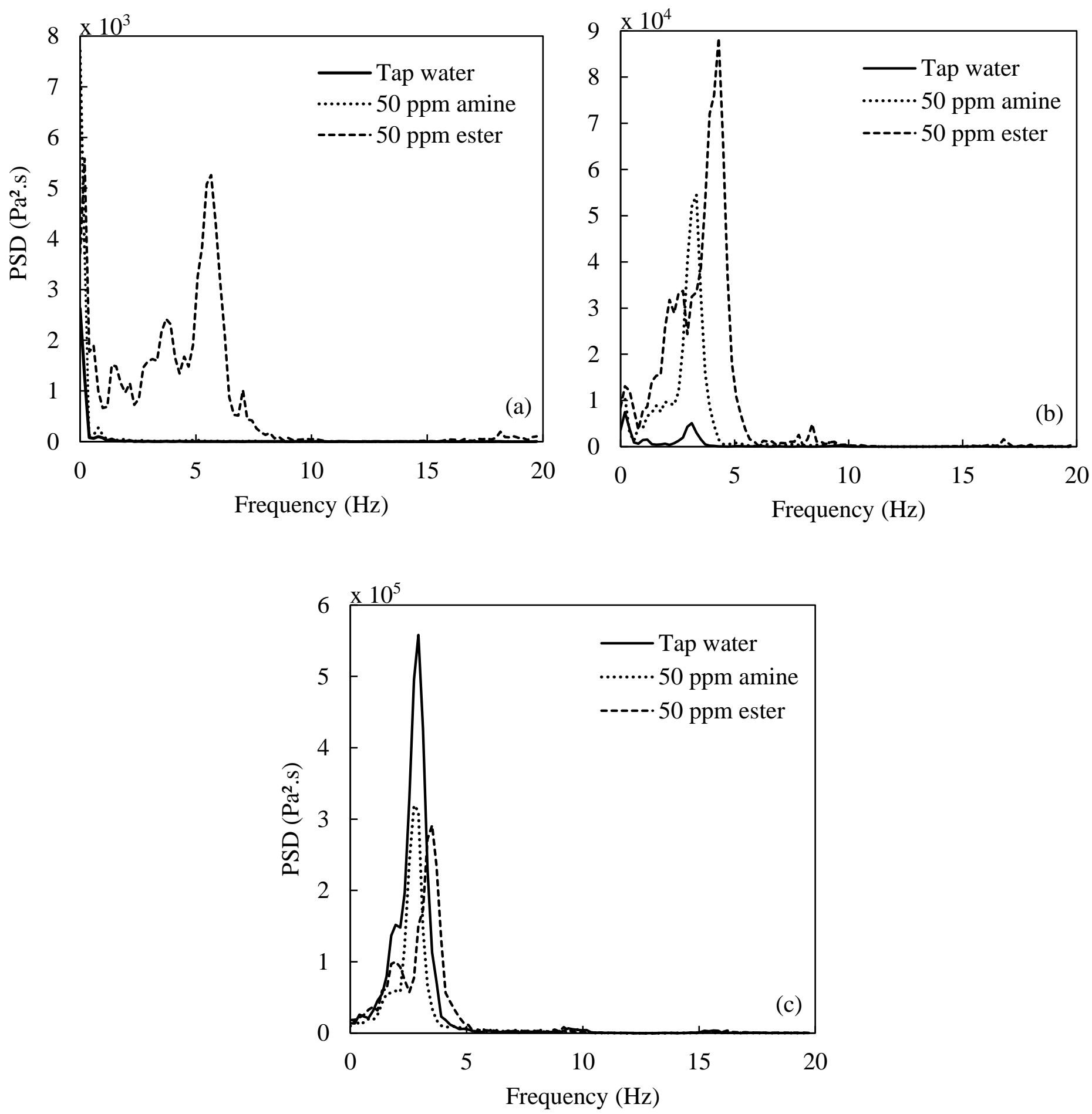

Fig. 8. Power spectral density of the pressure time series for different operating aqueous solutions at superficial gas velocity (a) $2.23 \mathrm{~cm} \cdot \mathrm{s}^{-1}$, (b) $5.42 \mathrm{~cm} \cdot \mathrm{s}^{-1}$, and (c) $9.44 \mathrm{~cm} \cdot \mathrm{s}^{-1}$. 


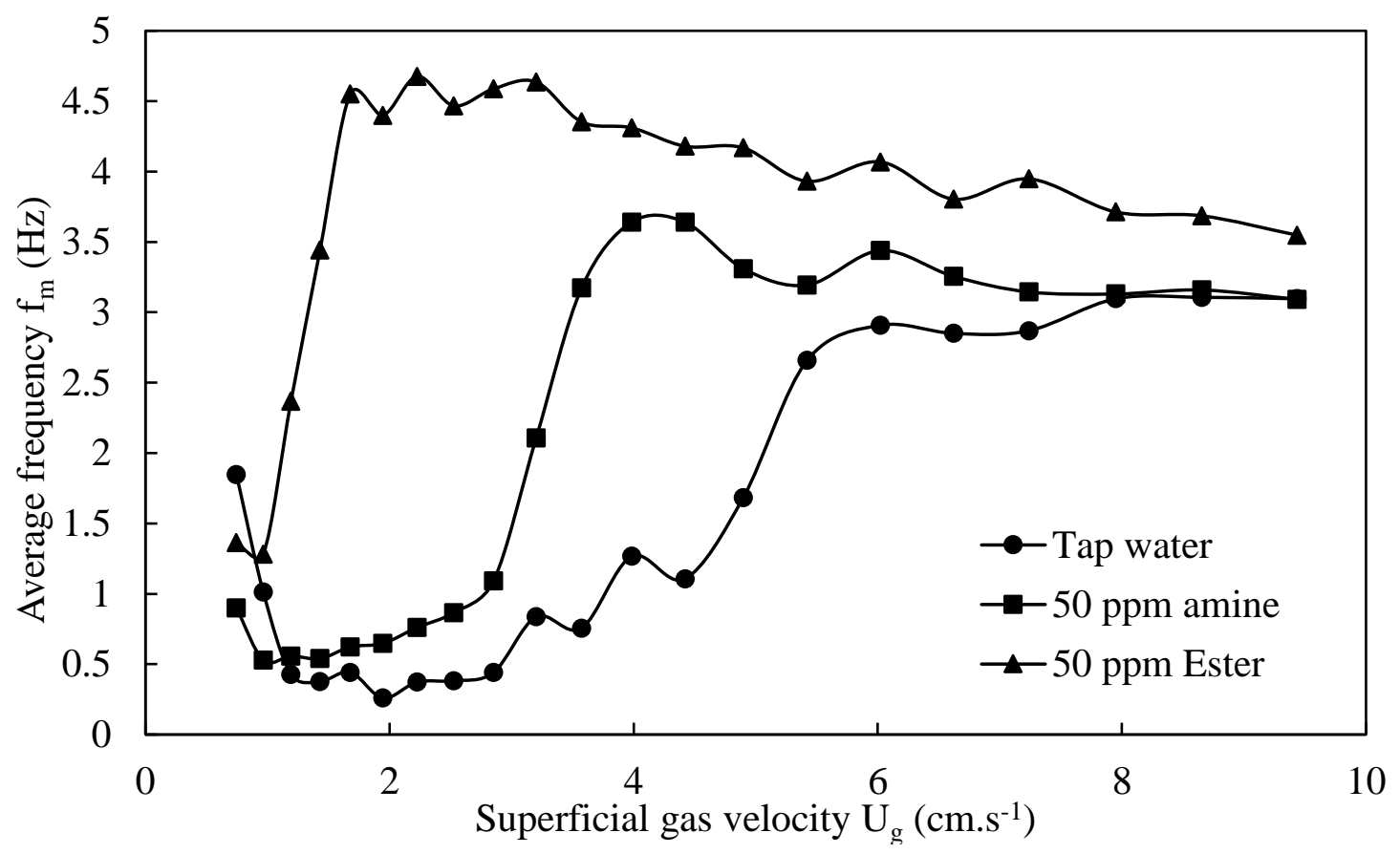

Fig. 9. Average frequency of the spectrum versus superficial gas velocity for tap water and surfactant aqueous solutions.

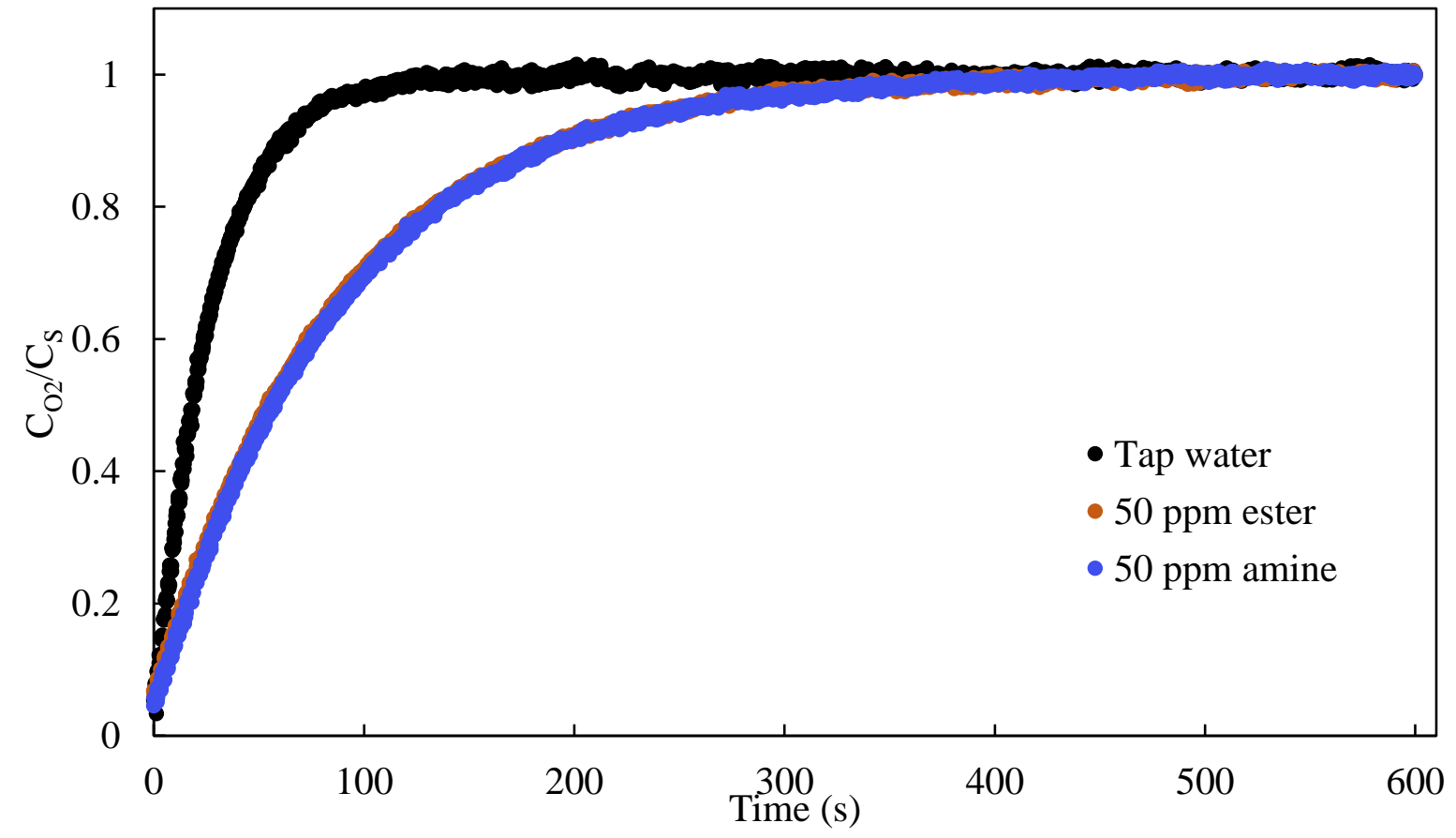

Fig. 10. Temporal variation of dissolved oxygen curves in tap water and collector aqueous solutions. 


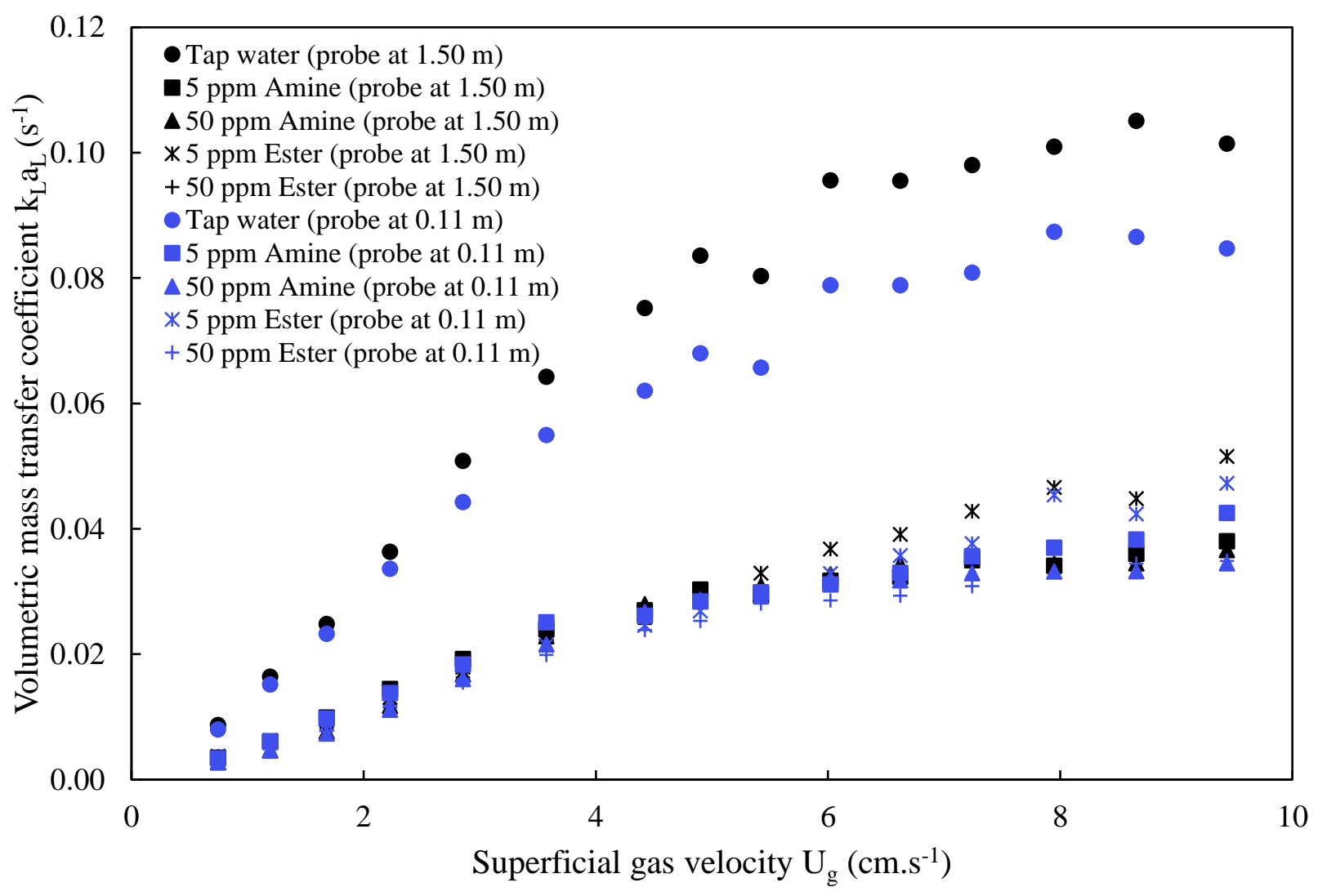

Fig. 11. Volumetric mass transfer coefficient $\mathrm{k}_{\mathrm{L}} \mathrm{a}_{\mathrm{L}}$ versus the superficial gas velocity for tap water and surfactant aqueous solutions.
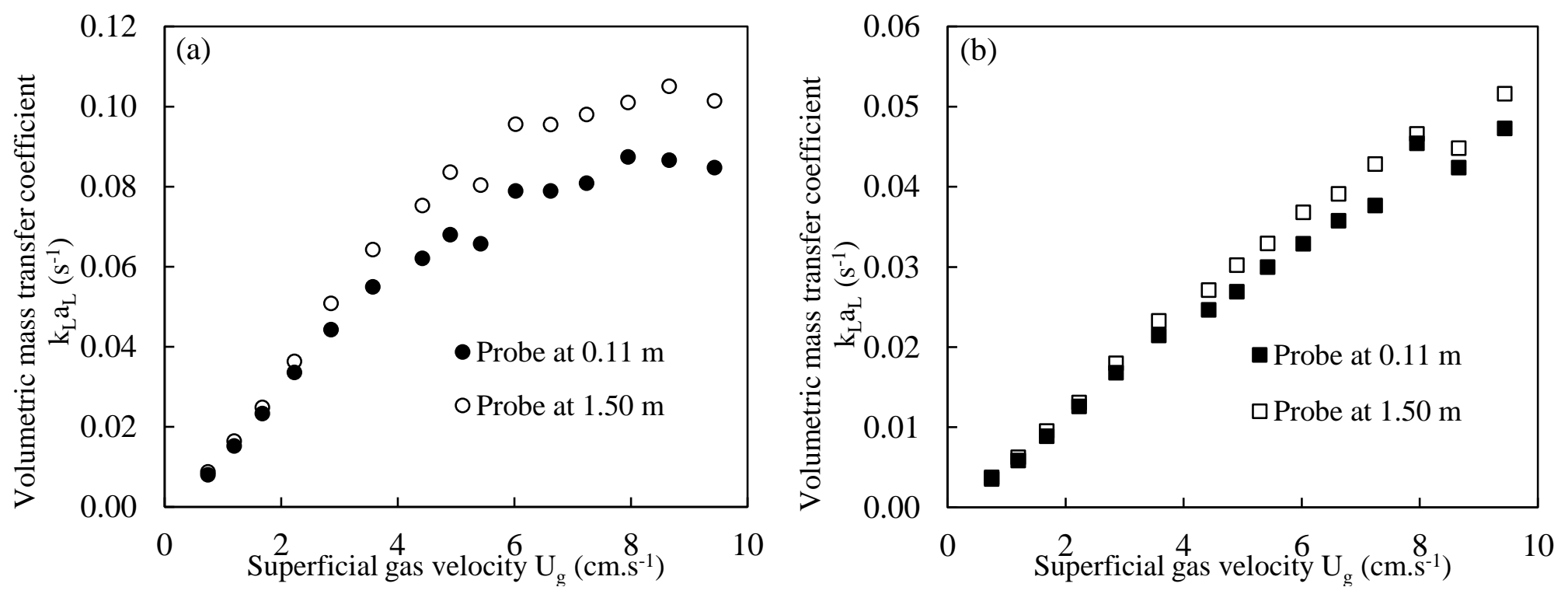

Fig. 12. Effect of the oxygen sensor position on the volumetric mass transfer coefficient $\mathrm{k}_{\mathrm{L}} \mathrm{a}_{\mathrm{L}}$

((a) tap water-air, and (b) 5 ppm ester-tap water-air). 


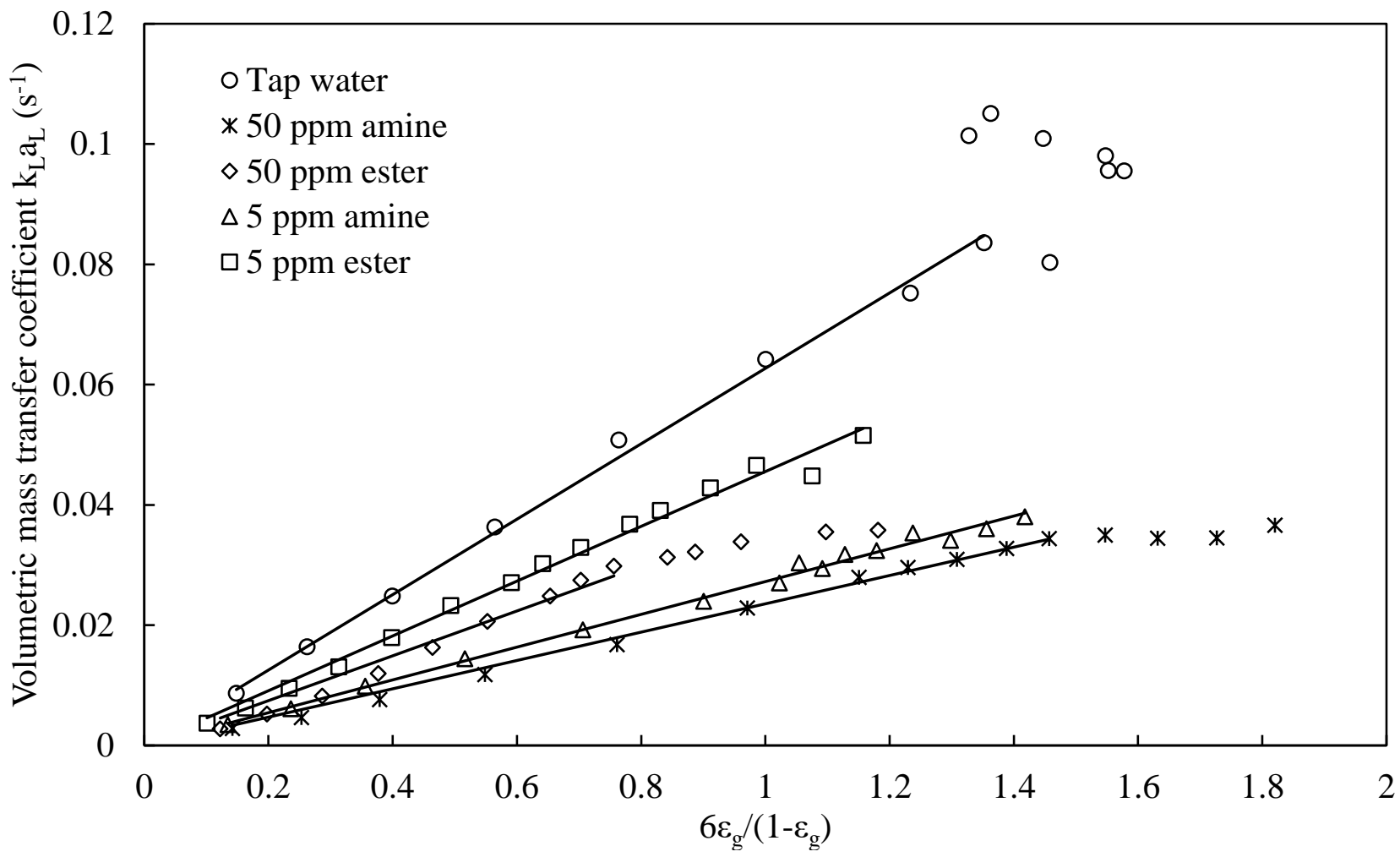

Fig. 13. Correlation of the measured $\mathrm{k}_{\mathrm{L}} \mathrm{a}_{\mathrm{L}}$ and gas hold-up $\varepsilon_{\mathrm{g}}$ according to Eq. (10). 
Table 1 Hold-up correlations in literature.

\begin{tabular}{|c|c|c|c|c|}
\hline Correlations & Medium & Operating conditions & $\begin{array}{l}\text { Sparger and column } \\
\text { design }\end{array}$ & References \\
\hline$\varepsilon_{\mathrm{g}}=\frac{1}{2+\left(\frac{0.35}{\mathrm{U}_{\mathrm{g}}}\right)\left[\left(\frac{\rho_{\mathrm{L}}}{1}\right)\left(\frac{\sigma}{72}\right)\right]^{1 / 3}}$ & $\begin{array}{l}\text { Water - air } \\
\text { Air - oil blend } \\
\text { Air }-\mathrm{ZnCl}_{2} \text { aq. sol. } \\
\text { Air }-\mathrm{Na}_{2} \mathrm{SO}_{3} \text { aq. sol. } \\
\text { Air - glycerol } \\
\text { Air - kerosene }\end{array}$ & $\begin{array}{l}\mathrm{U}_{\mathrm{g}}=0.04-45 \mathrm{~cm} \cdot \mathrm{s}^{-1} \\
\rho_{\mathrm{L}}=0.780-1.700 \mathrm{~g} \cdot \mathrm{cm}^{-3} \\
\sigma=25-76 \mathrm{mN} \cdot \mathrm{m}^{-1} \\
\mu_{\mathrm{L}}=0.0009-0.0152 \text { Pa.s }\end{array}$ & $\begin{array}{l}\mathrm{d}_{\mathrm{c}}>10 \mathrm{~cm} \\
\text { Multi-orifice gas } \\
\text { sparger }\end{array}$ & Hughmark [42] \\
\hline $\begin{array}{l}\frac{\varepsilon_{\mathrm{g}}}{\left(1-\varepsilon_{\mathrm{g}}\right)^{4}}=\mathrm{C}_{1}\left(\frac{\mathrm{gd}_{\mathrm{c}}^{2} \rho_{\mathrm{L}}}{\sigma}\right)^{1 / 8}\left(\frac{\mathrm{gd}_{\mathrm{c}}^{3}}{v_{\mathrm{L}}^{2}}\right)^{1 / 12}\left(\frac{\mathrm{U}_{\mathrm{g}}}{\sqrt{\mathrm{gd}_{\mathrm{c}}}}\right) \\
\text { where } \mathrm{C}_{1}=0.20 \text { for non-electrolyte systems, } \\
\mathrm{C}_{1}=0.25 \text { for electrolyte systems. }\end{array}$ & $\begin{array}{l}\text { Water }- \text { air } \\
\text { Water }+40 \% \text { vol methanol - air } \\
\mathrm{NaCl} \text { aq. sol. - air } \\
\text { Water }+70 \% \text { vol glycol - air } \\
\text { Water }-\mathrm{O}_{2} \\
\text { Water }-\mathrm{CO}_{2} \\
\text { Water }-\mathrm{He}\end{array}$ & $\begin{array}{l}\mathrm{U}_{\mathrm{g}}=1-24.75 \mathrm{~cm} \cdot \mathrm{s}^{-1} \\
\rho_{\mathrm{L}}=0.79-1.59 \mathrm{~g} \cdot \mathrm{cm}^{-3} \\
\sigma=22-74.2 \mathrm{mN} \cdot \mathrm{m}^{-1} \\
\mu_{\mathrm{L}}=0.00058-0.0211 \\
\text { Pa.s }\end{array}$ & $\begin{array}{l}\mathrm{d}_{\mathrm{c}}=15.2 \mathrm{~cm} \\
\text { Single-hole gas } \\
\text { sparger }\left(\mathrm{d}_{0}=0.5 \mathrm{~cm}\right)\end{array}$ & $\begin{array}{l}\text { Akita and Yoshida } \\
\text { [54] }\end{array}$ \\
\hline$\varepsilon_{\mathrm{g}}=0.505 \mathrm{U}_{\mathrm{g}}^{0.47}\left(\frac{72}{\sigma}\right)^{2 / 3}\left(\frac{1}{\mu_{\mathrm{L}}}\right)^{0.05}$ & $\begin{array}{l}\text { Water }- \text { air } \\
8 \text { wt } \% \text { aq. methanol sol. - air } \\
15 \mathrm{wt} \% \text { aq. methanol sol. - air } \\
53 \mathrm{wt} \% \text { aq. methanol sol. - air } \\
35 \mathrm{wt} \% \text { aq. cane sugar sol. - air } \\
50 \mathrm{wt} \% \text { aq. cane sugar sol. - air }\end{array}$ & $\begin{array}{l}\mathrm{U}_{\mathrm{g}}=4.30-33.80 \mathrm{~cm} \cdot \mathrm{s}^{-1} \\
\rho_{\mathrm{L}}=0.911-1.233 \mathrm{~g} \cdot \mathrm{cm}^{-3} \\
\sigma=38.2-75.5 \mathrm{mN} \cdot \mathrm{m}^{-1} \\
\mu_{\mathrm{L}}=0.001-0.0192 \text { Pa.s }\end{array}$ & $\begin{array}{l}\mathrm{d}_{\mathrm{c}}=10 \text { and } 19 \mathrm{~cm} \\
\mathrm{H}_{\mathrm{c}}=150 \text { and } 240 \mathrm{~cm} \\
- \text { Single nozzle gas } \\
\text { sparger }\left(\mathrm{d}_{0}=1.3 \mathrm{~cm}\right) \\
\text { - Three nozzles gas } \\
\text { sparger }\left(\mathrm{d}_{0}=1.31\right. \\
2.06 \text { and } 3.62 \mathrm{~cm})\end{array}$ & $\begin{array}{l}\text { Hikita and } \\
\text { Hikukawa [41] }\end{array}$ \\
\hline $\begin{array}{l}\varepsilon_{\mathrm{g}}=0.728 \mathrm{U}^{*}-0.485 \mathrm{U}^{* 2}+0.0975 \mathrm{U}^{* 3} \\
\text { Where } \mathrm{U}^{*}=\mathrm{U}_{\mathrm{g}}\left[\rho_{\mathrm{L}}^{2} / \sigma\left(\rho_{\mathrm{L}}-\rho_{\mathrm{g}}\right) \mathrm{g}\right]^{1 / 4}\end{array}$ & $\begin{array}{l}\text { Water-air } \\
40 \% \text { aq. glycerol sol. - air } \\
\text { Kerosene - air } \\
\text { Reacting system: Air/CO }- \text { aq. } \\
\mathrm{NaOH} \text { sol. }(2 \mathrm{M})\end{array}$ & $\begin{array}{l}\mathrm{U}_{\mathrm{g}}=0.22-6.89 \mathrm{~cm} \cdot \mathrm{s}^{-1} \\
\rho_{\mathrm{L}}=0.787-1.108 \mathrm{~g} \cdot \mathrm{cm}^{-3} \\
\sigma=31.19-74.5 \mathrm{mN} \cdot \mathrm{m}^{-1} \\
\mu_{\mathrm{L}}=0.00088-0.0115 \\
\text { Pa.s }\end{array}$ & $\begin{array}{l}\mathrm{d}_{\mathrm{c}}=5-10 \mathrm{~cm} \\
\text { Perforated plate }\left(\mathrm{d}_{0}=\right. \\
0.087-0.309 \mathrm{~cm})\end{array}$ & Kumar et al. [40] \\
\hline$\frac{\varepsilon_{\mathrm{g}}}{1-\varepsilon_{\mathrm{g}}}=0.115\left(\frac{\mathrm{U}_{\mathrm{g}}^{3}}{v_{\mathrm{L}} \mathrm{g}\left(\rho_{\mathrm{L}}-\rho_{\mathrm{g}}\right) / \rho_{\mathrm{L}}}\right)^{0.23}$ & $\begin{array}{l}\text { N-octanol - air } \\
\text { Tetrabromo-methane - air } \\
\text { 1,3-butanediol - air } \\
\text { Glycol aq. sol. - air }\end{array}$ & $\mathrm{U}_{\mathrm{g}}=1-20 \mathrm{~cm} \cdot \mathrm{s}^{-1}$ & $\begin{array}{l}\mathrm{d}_{\mathrm{c}}=10 \mathrm{~cm} \\
\mathrm{H}_{\mathrm{c}}=120 \mathrm{~cm}\end{array}$ & $\begin{array}{l}\text { Schumpe and } \\
\text { Deckwer [55] }\end{array}$ \\
\hline
\end{tabular}


$\varepsilon_{\mathrm{g}}=0.239 \mathrm{U}_{\mathrm{g}}^{0.634} \mathrm{~d}_{\mathrm{C}}^{-0.50}$

$\varepsilon_{\mathrm{g}}=296 \mathrm{U}_{\mathrm{g}}^{0.44} \rho_{\mathrm{L}}^{-0.98} \sigma^{-0.16} \rho_{\mathrm{g}}^{0.19}+0.009$

$\varepsilon_{\mathrm{g}}=3.38\left(\frac{\mathrm{U}_{\mathrm{g}}^{2}}{\mathrm{gd}_{\mathrm{C}}}\right)^{1 / 3}$
Carboxy-methyl cellulose sol. air

Glycerine aq. sol. - air

Water - air
Varsol (hydrocarbon oil) - air
Trichloroethylene - air

Water - air

Glycerine aq. sol. - air

Dextrose aq. sol - air

Fermentation medium (glucose + mineral salt)

Fermentation medium (molasses + mineral salt)

Fermentation medium (Alpha-floc + mineral salt)

Carboxy-methyl cellulose sol. -

air

Carboxypolymethylene sol. - air

Polyacrylamide sol. - air

Water - air

Viscous Newtonian fluids - air

Non-Newtonian fluids - air
$\mathrm{U}_{\mathrm{g}}=4-28 \mathrm{~cm} \cdot \mathrm{s}^{-1}$

$\rho_{\mathrm{L}}=0.996-1.008 \mathrm{~g} . \mathrm{cm}^{-3}$

$\mu_{\mathrm{L}}=0.0013-0.246$ Pa.s

$\mathrm{U}_{\mathrm{g}}=1-40 \mathrm{~cm} \cdot \mathrm{s}^{-1}$

$\rho_{\mathrm{L}}=0.788-1.468 \mathrm{~g} . \mathrm{cm}^{-3}$

$\sigma=28.3-72 \mathrm{mN} \cdot \mathrm{m}^{-1}$

$\mu_{\mathrm{L}}=(0.609-1.236) \times 10^{3}$

Pa.s

$\rho_{\mathrm{L}}=0.991-1.009 \mathrm{~g} . \mathrm{cm}^{-3}$

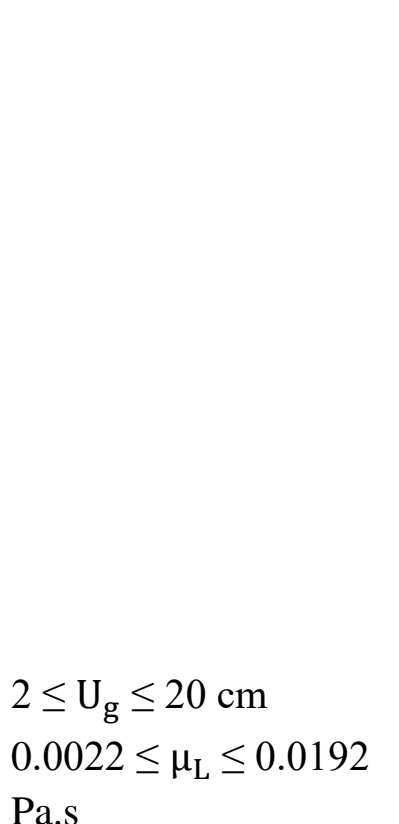

Pa.s

$\mathrm{d}_{\mathrm{c}}=30.5 \mathrm{~cm}$

Godbole et al. [56]

$\mathrm{H}_{\mathrm{c}}=244 \mathrm{~cm}$

Perforated plate (749

holes with $\mathrm{d}_{0}=0.166$

$\mathrm{cm}$ )

$\mathrm{d}_{\mathrm{c}}=30 \mathrm{~cm}$

Perforated distributor plate (293 holes with

$\left.\mathrm{d}_{0}=0.15 \mathrm{~cm}\right)$

- 40 L bubble column

$\mathrm{d}_{\mathrm{c}}=23 \mathrm{~cm}$

$\mathrm{H}_{\mathrm{c}}=122 \mathrm{~cm}$

Perforated plate $(20$

holes with $\mathrm{d}_{0}=0.1$

$\mathrm{cm}$ )

- 100 L pilot plant

fermenter

$\mathrm{d}_{\mathrm{c}}=76 \mathrm{~cm}$

$\mathrm{H}_{\mathrm{c}}=321 \mathrm{~cm}$

Ring sparger (100

holes with $\mathrm{d}_{0}=0.3$

$\mathrm{cm}$ )

$20 \leq \mathrm{d}_{\mathrm{c}} \leq 550 \mathrm{~cm}$

Kawase et al. [58]

Reilly et al. [43]

Kawase and MooYoung [57] 
Table 2 A few studies that used the pressure fluctuation methods for regime flow identification in bubble columns.

\begin{tabular}{|c|c|c|c|c|}
\hline Authors & Medium & $\begin{array}{l}\text { Column } \\
\text { dimension }(\mathrm{cm})\end{array}$ & Methods & Highlights \\
\hline Vial et al. [17] & Water - air & $\begin{array}{l}\mathrm{d}_{\mathrm{c}}=10 \\
\mathrm{H}_{\mathrm{c}}=200\end{array}$ & $\begin{array}{l}\text { - Statistical analysis } \\
\text { - Spectral analysis } \\
\text { - Fractal analysis } \\
\text { - Chaos analysis }\end{array}$ & $\begin{array}{l}\text { - Statistical analysis can detect the transition, but it does not provide more } \\
\text { information than conventional methods based on gas hold-up } \\
\text { measurements. } \\
\text { - Spectral analysis is able to identify the governing flow regime in the } \\
\text { bubble reactor (with the perforated or the porous plates, the homogeneous } \\
\text { flow was characterized by a peak at } 0.1 \mathrm{~Hz} \text {, whereas the heterogeneous } \\
\text { regime by } 3-5 \mathrm{~Hz} \text { ) } \\
\text { - Fractal and particularly chaos approaches accurately indicate the } \\
\text { transition regime. }\end{array}$ \\
\hline Lin et al. [59] & Water - air & $\begin{array}{l}\mathrm{d}_{\mathrm{c}}=17 \\
\mathrm{H}_{\mathrm{c}}=250\end{array}$ & - Chaos analysis & $\begin{array}{l}\text { Four chaotic invariants (Lyapunov exponent, metric entropy, correlation } \\
\text { dimension, and mutual information) were used to identify the transition } \\
\text { velocity. Two transitions velocities were found; } 4 \text { and } 10 \mathrm{~cm} \cdot \mathrm{s}^{-1} \text {. }\end{array}$ \\
\hline $\begin{array}{l}\text { Gourich et al. } \\
{[11]}\end{array}$ & $\begin{array}{l}\text { Water - air } \\
\text { Aqueous alcohol } \\
\text { solutions - air }\end{array}$ & $\begin{array}{l}\mathrm{d}_{\mathrm{c}}=10 \\
\mathrm{H}_{\mathrm{c}}=300\end{array}$ & $\begin{array}{l}\text { - Standard deviation } \\
\text { - Spectral analysis } \\
\text { - Fractal analysis } \\
\text { - Chaos analysis }\end{array}$ & $\begin{array}{l}\text { Pressure fluctuation methods successfully identify the boundary of flow } \\
\text { regimes but there is no clear transition. }\end{array}$ \\
\hline $\begin{array}{l}\text { Chilekar et al. } \\
\text { [60] }\end{array}$ & $\begin{array}{l}\text { Demineralized } \\
\text { water - air }\end{array}$ & $\begin{array}{l}\mathrm{d}_{\mathrm{c}}=30 \\
\mathrm{H}_{\mathrm{c}}=200\end{array}$ & $\begin{array}{l}\text { - Power spectral } \\
\text { density }\end{array}$ & $\begin{array}{l}\text { Large bubbles of } 4 \text { to } 5 \mathrm{~cm} \text { generate pressure fluctuations in the range of } 2 \\
\text { to } 5 \mathrm{~Hz} \text {, and that small bubbles of around } 4 \mathrm{~mm} \text { can induce fluctuations up } \\
\text { to } 50 \mathrm{~Hz} \text {. }\end{array}$ \\
\hline $\begin{array}{l}\text { Sheikhi et al. } \\
{[15]}\end{array}$ & Tap water - air & $\begin{array}{l}\mathrm{d}_{\mathrm{c}}=9 \\
\mathrm{H}_{\mathrm{c}}=200\end{array}$ & $\begin{array}{l}\text { - Statistical analysis } \\
\text { - Spectral analysis }\end{array}$ & $\begin{array}{l}\text {-The analysis of the signals in the frequency domain suggested the way of } \\
\text { the alteration of the behavior of the bubbles according to their size under } \\
\text { different operating conditions of gas and liquid velocities. } \\
\text { - The kurtosis of pressure fluctuations could only detect the main transition } \\
\text { point of the column at moderate liquid velocities. }\end{array}$ \\
\hline $\begin{array}{l}\text { Tchowa } \\
\text { Medjiade et al. } \\
\text { [36] }\end{array}$ & Water - nitrogen & $\begin{array}{l}\mathrm{d}_{\mathrm{c}}=10.2 \\
\mathrm{H}_{\mathrm{c}}=240\end{array}$ & $\begin{array}{l}\text { - Standard deviation } \\
\text { - Fractal analysis } \\
\text { - Kolmogorov entropy } \\
\text { - Power spectral } \\
\text { density }\end{array}$ & $\begin{array}{l}\text { - The homogeneous regime was characterized by a zone without any peaks. } \\
\text { - The heterogeneous flow was characterized by the presence of pronounced } \\
\text { spikes at up to } 20 \mathrm{~s}^{-1} \text { and less pronounced peaks from } 35 \text { to } 45 \mathrm{~s}^{-1} \text {. } \\
\text { - The transition between the two-above mentioned regimes was observed at } \\
4.5 \mathrm{~cm} \cdot \mathrm{s}^{-1} \text {. }\end{array}$ \\
\hline
\end{tabular}


Table 3 Surface tension and apparent viscosity of the liquid phases at $25^{\circ} \mathrm{C}$.

\begin{tabular}{llll}
\hline Aqueous solution & Concentration $(\mathrm{ppm})$ & Surface tension $\left(\mathrm{mN} . \mathrm{m}^{-1}\right)$ & Apparent viscosity $(\mathrm{mPa} . \mathrm{s})$ \\
\hline Tap water & - & $72.9 \pm 0.9$ & $1.10 \pm 0.05$ \\
\hline Amine & 5 & $63.1 \pm 1.4$ & $1.20 \pm 0.15$ \\
& 10 & $48.4 \pm 1.8$ & $1.11 \pm 0.01$ \\
& 15 & $43.5 \pm 1.8$ & $1.11 \pm 0.01$ \\
& 20 & $29.9 \pm 1.6$ & $1.10 \pm 0.01$ \\
& 30 & $30.3 \pm 1.7$ & $1.11 \pm 0.13$ \\
& 40 & $28.9 \pm 0.9$ & $1.09 \pm 0.02$ \\
& 50 & $28.5 \pm 0.5$ & $1.10 \pm 0.09$ \\
\hline Ester & 5 & $55.0 \pm 1.5$ & $1.20 \pm 0.14$ \\
& 10 & $55.1 \pm 1.5$ & $1.13 \pm 0.05$ \\
& 15 & $48.5 \pm 1.2$ & $1.10 \pm 0.04$ \\
& 20 & $40.8 \pm 0.8$ & $1.10 \pm 0.03$ \\
& 30 & $34.0 \pm 1.4$ & $1.11 \pm 0.08$ \\
& 40 & $34.3 \pm 1.3$ & $1.10 \pm 0.04$ \\
& 50 & $32.7 \pm 0.7$ & $1.09 \pm 0.02$ \\
\hline
\end{tabular}

Table 4 Comparison of $\mathrm{k}_{\mathrm{L}} / \mathrm{d}_{\mathrm{B}}$ ratio for tap water and surfactant aqueous solutions.

\begin{tabular}{lc}
\hline System & $\mathrm{k}_{\mathrm{L}} / \mathrm{d}_{\mathrm{B}}\left(\mathrm{s}^{-1}\right)$ \\
\hline Air-tap water & $0.063 ; \mathrm{R}^{2}=99.67$ \\
Air-tap water-5 ppm amine & $0.027 ; \mathrm{R}^{2}=99.42$ \\
Air-tap water-50 ppm amine & $0.024 ; \mathrm{R}^{2}=99.48$ \\
Air-tap water-5 ppm ester & $0.046 ; \mathrm{R}^{2}=99.01$ \\
Air-tap water-50 ppm ester & $0.037 ; \mathrm{R}^{2}=97.04$ \\
\hline
\end{tabular}

Table 5 Comparison bubble size estimation using image analysis at $\mathrm{U}_{\mathrm{g}}=1.2 \mathrm{~cm} / \mathrm{s}$.

\begin{tabular}{ccc}
\hline & $\begin{array}{c}\text { Mean bubble } \\
\text { size }(\mathrm{mm})\end{array}$ & $\begin{array}{c}\text { Standard deviation of bubble } \\
\text { size distribution }(\mathrm{mm})\end{array}$ \\
\hline Tap water & 5.6 & 1.2 \\
Amine - 5 ppm & 2.8 & 1.2 \\
Amine - 50 ppm & 2.6 & 1.3 \\
Ester - 5 ppm & 1.9 & 1.1 \\
Ester - 50 ppm & 6.7 & 3.2 \\
\hline
\end{tabular}

